\title{
IBIZA NIGHTLIFE: DESCRIPCIÓN DE UN REFERENTE MUNDIAL EN SU SECTOR
}

\author{
Ramón Cardona, José ${ }^{1}$ \\ Azpelicueta Criado, María del Carmen ${ }^{2}$ \\ Serra Cantallops, Antoni $^{3}$ \\ Universitat de les Illes Balears \\ iramon.cardona@terra.com \\ m.azpelicueta@uib.eu \\ antoni.serra@uib.es
}

Material original autorizado para su primera publicación en la revista académica REDMARKA. Revista Digital de Marketing Aplicado. https://doi.org/10.17979/redma.2015.01.015.4885

Recibido: 16 Marzo 2015

Aceptado 27 Julio 2015

\section{RESUMEN}

${ }^{1}$ Licenciado en Administración y Dirección de Empresas, Licenciado en Economía y Doctor en Economía de la Empresa por la Universitat de les Illes Balears. Miembro del Grupo de Investigación en Dirección y Gestión de Empresas y Destinos Turísticos.

${ }^{2}$ Licenciada en Ciencias del Trabajo, Graduada Social Diplomada y Becaria FPU de Economía de la Empresa en la Universitat de les Illes Balears. Miembro del Grupo de Investigación en Dirección y Gestión de Empresas y Destinos Turísticos.

${ }^{3}$ Licenciado en Ciencias Económicas por la UNED, Master of Business Administration por la Middlesex University y Doctor en Economía por la Universitat de les Illes Balears. Profesor Titular de Comercialización e Investigación de Mercados en la Universitat de les Illes Balears e Investigador Principal del Grupo de Investigación en Dirección y Gestión de Empresas y Destinos Turísticos.

REDMARKA UIMA-Universidad de A Coruña - CIECID

Año VIII, Número 15, (2015), v I pp. 101-139

http://www.redmarka.net/ ISSN 1852-2300 
Los estudios que toman como protagonista la oferta de ocio nocturno son escasos y puramente descriptivos. Ibiza es conocida mundialmente por sus discotecas y sus fiestas. El objetivo de este trabajo es realizar una primera aproximación a la historia del sector en Ibiza, su relevancia mundial y una descripción de la actual oferta de ocio nocturno. Los orígenes del sector se encuentran a finales de los años cincuenta, pero las discotecas aparecieron en los setenta. La imagen de isla de fiesta sería difícil de explicar sin el auge de los ochenta. En los noventa se formó un grupo de establecimientos que son referentes mundiales. El liderazgo de la oferta de la isla se plasma en su importante presencia en los premios de la Winter Music Conference y en el listado Top 100 Clubs de DjMag. La oferta de ocio nocturno se estructura básicamente en preparties, parties y, a veces, afters. El éxito del sector se fundamenta en empresarios y establecimientos con una larga trayectoria y una importante política de reinversión e innovación. Pero su mayor relevancia se encuentra en su capacidad de atracción de turistas. El turismo clubber es el principal complemento del turismo de sol y playa. Juntos representan la mayor parte del negocio turístico de la isla. Por lo tanto, el actual modelo turístico depende tanto de estos establecimientos.

Palabras Clave: Ibiza, ocio nocturno, descripción.

\section{ABSTRACT}

IBIZA NIGHTLIFE: DESCRIPTION OF A WORLD REFERENCE IN ITS SECTOR

The studies that take as its protagonist the nightlife supply are scarce and purely descriptive. Ibiza is known worldwide for its nightclubs and festivals. The objective of this work is a first approach to the history of the industry in Ibiza, its global relevance and a description of the current nightlife supply. The origins of the sector are in the late fifties, but the clubs appeared in the seventies. The image of Party Island would be difficult to explain without the boom of the

Año VIII, Número 15, (2015), v I pp. 101-139

http://www.redmarka.net/ ISSN 1852-2300 
eighties. In the nineties was formed a group of establishments that are worldwide references. The supply leadership of the island is reflected in its strong presence in the Winter Music Awards Conference and the DJMag Top 100 Clubs list. The nightlife supply is basically structured in preparties, parties and, sometimes, afters. The success of the sector is based on entrepreneurs and establishments with a long history and an important policy of reinvestment and innovation. But its greatest relevance lies in its ability to attract tourists. Clubber tourism is the principal complement of sun and beach tourism. Together they represent the largest part of the tourist business on the island. Therefore, the current tourism model depends both of these establishments.

Key Words: Ibiza, nightlife, description. 


\section{INTRODUCCIÓN}

El sector de las discotecas y el ocio nocturno no posee excesiva bibliografía académica y la mayor parte de ella hace referencia a las discotecas como elemento del contexto en que se estudia otro fenómeno. Ejemplos de ello son diversos estudios sobre consumo de drogas, alcohol y tabaco (Forsyth, 2009; Tutenges, 2012), conductas violentas (Anderson, et al., 2009; Forsyth \& Lennox, 2010), fumadores pasivos (Fallin, et al., 2014; Jones, et al., 2013), drogas (Archer, et al., 2014; Norrgård, et al., 2014; Wood, et al., 2012), alcohol (Bancroft, 2012; Lea, et al., 2013; Wells, et al., 2010); relaciones sexuales de riesgo (Boyd, 2010; Goulding, et al., 2009; Sönmez, et al., 2013); violencia y seguridad (Anderson, et al., 2009; Demant, 2013; Romain-Glassey et al., 2012); accidentes o desastres (Aguirre, et al., 2011; Mahoney et al., 2005; Tutenges, 2009); problemas de salud diversos (Bar-Sela \& Moisseiev, 2007; Kramer et al., 2006); comportamientos sociales (Allemand, 2010; García, 2005; Réau, 2006); música y dj's (Forsyth, 2009); derechos de autor (Homan, 2010), y planificación urbana (Burke, \& Schmidt, 2013; Roberts \& Gornostaeva, 2007) en el contexto del ocio nocturno, discotecas y destinos de turismo clubber. Viendo la temática de las publicaciones que mencionan en su contenido a las discotecas se podría llegar a la conclusión de que sólo son un foco de problemas sociales y de salud, ya que en su inmensa mayoría es lo que analizan.

Los estudios que toman como protagonista el ocio nocturno, las discotecas y su gestión son muy escasos. Existen algunos estudios puramente descriptivos de la oferta de ocio nocturno en Taiwán (Huang, 2011), el sur de Londres (Andersson, 2011), Berlín (Bader \& Scharenberg, 2010), Belgrado (Todorovic \& Bakir, 2005), Milwaukee (Campo \& Ryan, 2008) y Los Ángeles (Hong \& Duff, 1997). Existe un estudio sobre disputas por derechos de autor entre discotecas y sociedades gestoras (Homan, 2010), estudios sobre las discotecas como lugar de trabajo (Sosteric, 1996), estudios históricos (Austin, 1994; Krasnow, 1999; Oak \& Schmidgall, 2009; Tuck, 2008), y un grupo de estudios sobre 
servicescape (Berkley, 1996; Kubacki, et al., 2007; McVeigh, 2004; Rose, 1994; Skinner, et al., 2008; Skinner, et al., 2005) que constituyen las únicas publicaciones de interés para estudiosos de la gestión y el turismo. No se han localizado hasta el momento estudios que analicen ninguna otra área de la gestión de discotecas y los pocos estudios existentes de servicescape se centran en el Reino Unido y Polonia. Existen algunos estudios etnográficos realizados en el contexto de las discotecas (Davis, 2008; Hendrie, et al., 2009; Réau, 2006; Weichbold \& Zorowka, 2005), estudiando las discotecas como un entorno de exhibición sexual (Hendrie, et al., 2009) y ostentación social (Davis, 2008; Réau, 2006).

A pesar de la importancia mundial de las discotecas y el ocio nocturno de Ibiza, los estudios académicos existentes poseen el mismo enfoque que en el resto del mundo, siendo un mero contexto para estudios sobre consumo de drogas, alcohol y tabaco (Bellis, et al., 2003; Bellis, et al., 2009; Elliott et al., 1998; Hughes et al., 2009), conductas violentas (Hughes et al., 2008) y relaciones sexuales de riesgo (Bellis \& Hughes, 2004; Downing et al., 2011; Elliott et al., 1998; Hughes \& Bellis, 2006). El objetivo de este trabajo es realizar una primera aproximación a la historia de este sector en la isla de lbiza, su relevancia mundial y una descripción de la oferta actual.

Esta trabajo es eminentemente descriptivo e historiográfico con lo cual se ha recurrido a la consulta de documentación (libros y prensa local, fundamentalmente), principalmente compuesta por testimonios de empresarios y promotores con larga experiencia en el sector, completado mediante observación. Del análisis de la historia del sector se observa que hay un origen en los cincuenta y sesenta vinculado a la colonia extranjera residente en la isla, pero el gran desarrollo se produce en los ochenta, al expandir sus negocios los empresarios surgidos en los setenta. En la actualidad hay un grupo de establecimientos de prestigio y relevancia mundial complementados por establecimientos de calidad diversa.

REDMARKA UIMA-Universidad de A Coruña - CIECID

Año VIII, Número 15, (2015), v I pp. 101-139

http://www.redmarka.net/ ISSN 1852-2300 


\section{ORÍGENES DEL OCIO NOCTURNO EN IBIZA}

Ibiza es una isla del mediterráneo occidental de 571,76 kilómetros cuadrados de superficie y 140.271 habitantes a 1 de enero de 2014 (Ibestat), caracterizada por su fuerte dependencia económica del turismo. Recibió 2,427.000 turistas en 2013, mayoritariamente concentrados en los meses de junio a septiembre. Los inicios del turismo en lbiza se encuentran en el primer tercio del siglo XX, pero fue entre la segunda mitad de los años cincuenta y los setenta cuando se produjo el gran boom turístico. El rápido crecimiento del sector se debe a que permitió abandonar la situación de pobreza anterior. Danielle Rozenberg resaltaba la importancia del turismo en la historia de Ibiza y comentaba que "los mismos ibicencos, para diferenciar el tiempo hablan de antes del turismo y de ahora. Saben que son dos épocas, dos eras muy distintas" (Planells, 1986, p. 33). El crecimiento del sector fue apoyado desde todos los ámbitos (administración, residentes, iglesia católica, empresariado, etc.) debido a las mejoras económicas que podía aportar. El turismo siguió creciendo rápidamente hasta que las leyes autonómicas frenaron el crecimiento de plazas turísticas a principios de los noventa y se estabilizaron los volúmenes de turistas hacia el año 2000, manteniéndose más o menos estables las cifras turísticas desde entonces. Esta limitación fue establecida para evitar rebasar las capacidades de carga del archipiélago y la destrucción total del entorno.

Desde sus inicios, Ibiza creció amparada por una imagen de libertad que atrajo a las vanguardias artísticas europeas en un primer momento y, posteriormente, a los beatniks y hippies. La isla se encontraba alejada de los centros de poder del país, permitiendo que las conductas reprobables por la moral del régimen franquista pasaran bastante desapercibidas. Además, los residentes tenían una actitud de inacción con los comportamientos poco acordes con sus creencias, básicamente porque existía una tradición de tolerancia. Este ambiente de libertad favoreció que existieran fiestas y locales nocturnos impensables por REDMARKA UIMA-Universidad de A Coruña - CIECID

Año VIII, Número 15, (2015), v I pp. 101-139

http://www.redmarka.net/ ISSN 1852-2300 
aquellos años, tanto en España como en Europa, y que personas de todo el mundo residieran en Ibiza. Estos extranjeros fueron la base para las primeras iniciativas de ocio nocturno.

El primer punto donde se desarrolló esta libertad, tanto para turistas como para residentes, fue en la Bahía de Sant Antoni. A causa de acontecimientos ocurridos durante los años de la guerra civil, en Sant Antoni se vivió una mayor permisividad que en otras partes de la isla. Ello conllevó que el primer desarrollo turístico de la isla se produjera en Sant Antoni, acumulando el $60 \%$ de la oferta y la demanda en 1960. Era una época en donde la ausencia de normas, el incumplimiento de las existentes y una cierta discreción de los individuos llevaron a la paradoja de que en una dictadura existiera mayor libertad que en algunas democracias. El ocio nocturno de la época estaba constituido por pequeños bares nocturnos con música y fiestas más o menos improvisadas en casas particulares o espacios naturales. Era el precedente del movimiento hippie (Ramón \& Serra, 2013).

A finales de los cincuenta y durante los sesenta, el gobierno nacional vio la importancia económica del turismo y fomentó la eliminación de trabas por parte de la administración al desarrollo del nuevo sector. Las sanciones por asuntos de moralidad no desaparecieron pero se relajaron enormemente en toda la isla. Ello hizo posible que en la ciudad de lbiza se desarrollara una oferta de ocio nocturno. Los sesenta fue la época dorada de bares como La Tierra, La Oveja Negra, The Tavern, Clive's o Domino (Planells, 2002). En 1959 abre el Domino que, junto al Clive's (abierto en 1967 al lado del Domino), inició el ambiente que aún hoy mantiene la zona del puerto. Eieter Loerzer, fundador del Domino lo contaba así:

"El Domino fue el primer bar extranjero con la música ambiental muy alta, incluso antes que California o Nueva York. Esta moda la introduje yo. La música muy alta, pero nuestra fama a los ojos de la policía era muy baja.... En 1960 ya se fumaba bastante, siguiendo la moda introducida por los REDMARKA UIMA-Universidad de A Coruña - CIECID

Año VIII, Número 15, (2015), v I pp. 101-139

http://www.redmarka.net/ ISSN 1852-2300 
americanos... tenía que echar a varios clientes al día, porque encendían el porro en el bar, tan tranquilos.... Yo tenía unos 2.000 elepés, con la mejor música del momento. Venía gente de todo tipo, desde los arquitectos como Walter Gropius y Erwin Broner, hasta marinos, pescadores, beats, personajes perdidos Dios sabe dónde y porqué. Cuando llegaba la flota francesa o la americana no solía haber problemas, porque ellos mismos llevan su policía militar, pero el Domino fue un bar salvaje, como del salvaje oeste, con la música muy alta, con alguna pelea, con fumadores de hachís, policías, negros, campesinos, alemanes y todo tipo de cosas y de gente. Fue el comienzo de la revolución hedonista de lbiza. Fuimos los pioneros en todo el mundo... lo de la música: íbamos por delante de Nueva York. Yo los encargaba o los cambiaba a algún intelectual o viajero que se había quedado sin dinero" (Planells, 2002, pp. 84-86).

En los sesenta y setenta las fiestas promovidas por la comunidad hippie toman una presencia importante y algunas de ellas se convierten en una tradición que aún perdura, como es el caso de la fiesta de los tambores en Benirràs o la celebración de la puesta del sol en Benirràs, Sant Antoni, Punta Galera, u otros puntos de la costa oeste. Entre finales de los sesenta y principios de los setenta abren las primeras discotecas o boîtes, destacando Pachá (Figura 1) y Glory's.

\section{Figura 1: Discoteca Pachá en los setenta.}

REDMARKA UIMA-Universidad de A Coruña - CIECID

Año VIII, Número 15, (2015), v I pp. 101-139

http://www.redmarka.net/ ISSN 1852-2300 


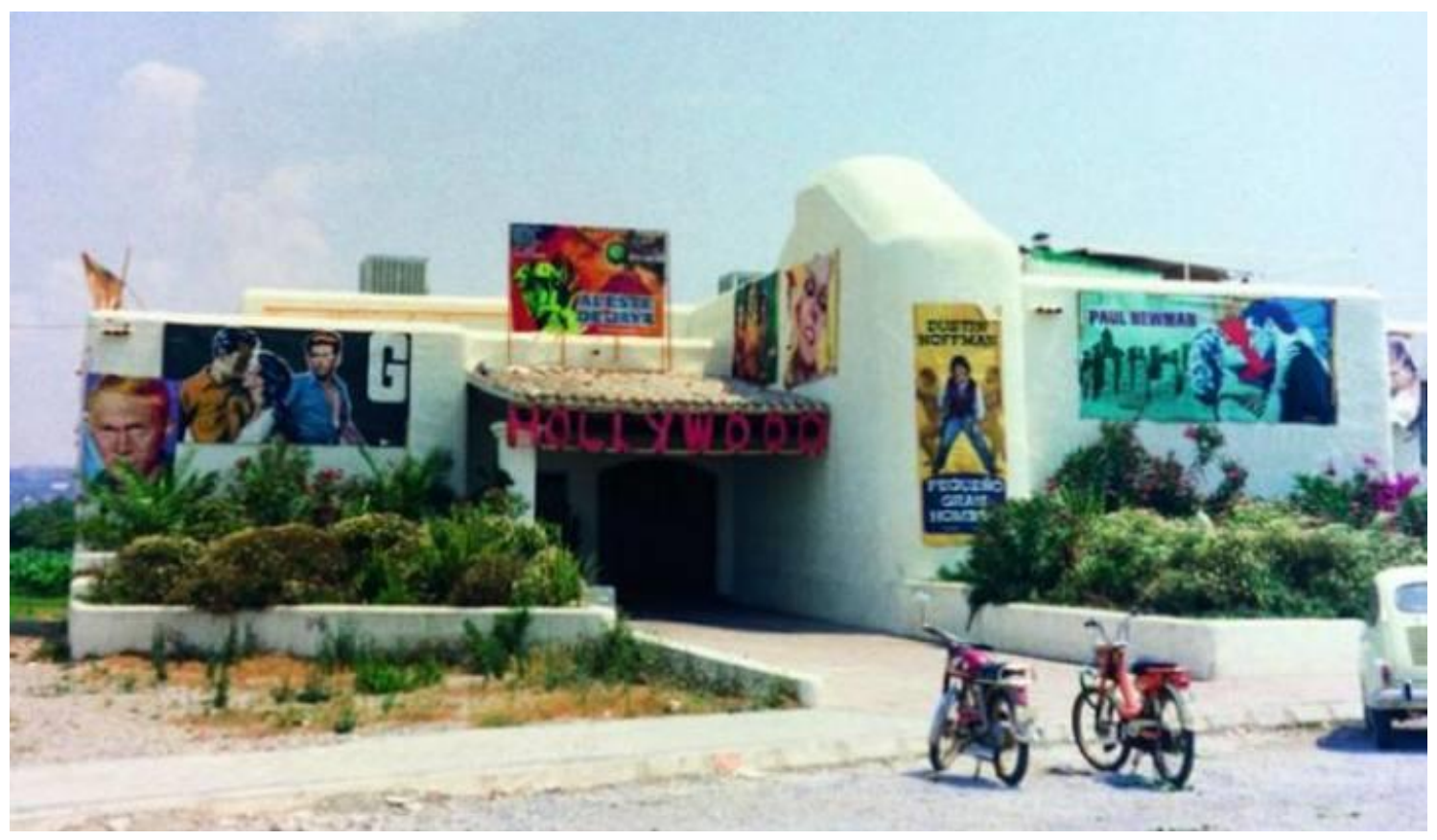

Fuente: Diario de lbiza y archivo Pachá.

En esta época la oferta estaba formada por pequeños locales, principalmente bares de Sant Antoni o la ciudad de Ibiza, con un tocadiscos y la iluminación más baja de lo que marcaba la normativa de la época. Cabe indicar que la gran innovación técnica de estos locales en los setenta fue trabajar con dos platos que permitían realizar las primeras mezclas. La gestión era poco profesional y basada en la improvisación y los contactos. Aún así la voluntad de los empresarios, la fraternidad de la comunidad extranjera y la actitud de los clientes consiguieron que el sector prosperase y que exista una añoranza por esa época entre los veteranos del sector. La oferta de la época no se basaba en la espectacularidad del local ni en las performances, ya que no existían. Tampoco en los pinchadiscos, que en aquella época tenían poca relevancia. La oferta se basaba en la interacción de unos clientes muy heterogéneos y activos, entre ellos estrellas de la época que en algunos casos dejaron constancia de su paso por la isla como indica Pino Sagliocco:

REDMARKA UIMA-Universidad de A Coruña - CIECID

Año VIII, Número 15, (2015), v I pp. 101-139

http://www.redmarka.net/ ISSN 1852-2300 
"El grupo Pink Floyd se inspiró en Formentera y se instaló en lbiza para componer algunas canciones, entre otras 'lbiza Bar', del disco 'More'. Artistas como los Bee Gees ensayaban sus nuevas canciones en el bar Ses Guitarres de San Antonio y Cat Stevens entonaba 'Moonshadow' en las terrazas del puerto de Ibiza.... Conciertos y visitas de grandes estrellas internacionales empiezan a forjar la leyenda de lbiza como isla de la música. Mike Oldfield se inspiró desde su casa frente a es Vedrá para componer sus obras maestras, Frank Zappa y King Crimson también recalaron en Ibiza. La cantante Joni Mitchell compone su disco 'Blue' y Nico, de Velvet Underground, se inspira en el ambiente único de la isla" (Diario de lbiza, 21 de agosto de 2013).

Figura 2: Discoteca Pachá en la actualidad.

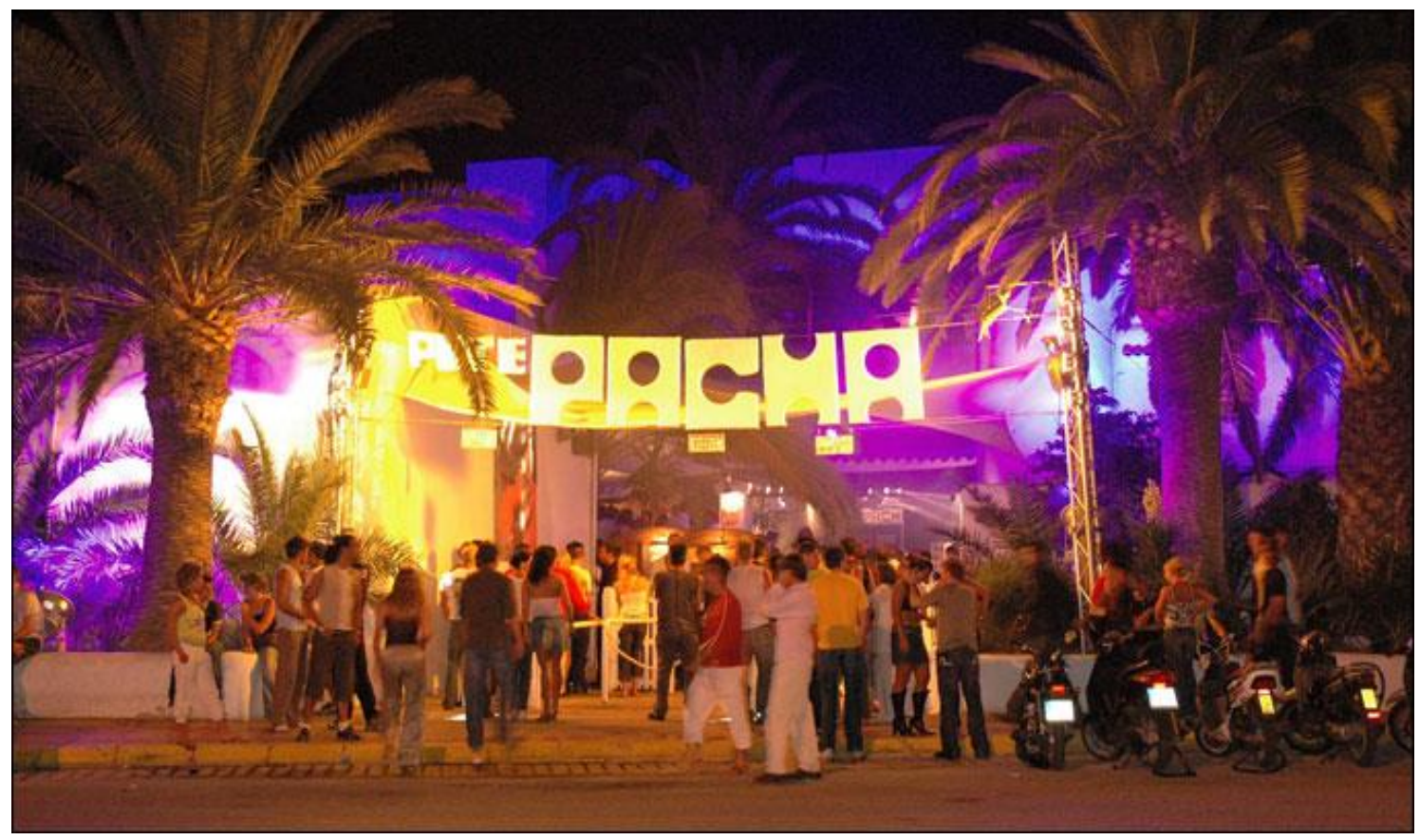

Fuente: web site Ibiza Isla.

REDMARKA UIMA-Universidad de A Coruña - CIECID

Año VIII, Número 15, (2015), v I pp. 101-139

http://www.redmarka.net/ ISSN 1852-2300 
Posiblemente el mejor ejemplo de cómo ha cambiado el sector con el paso de las décadas lo tenemos en Pachá Ibiza. La discoteca Pachá fue abierta en 1973 por Ricardo Urgell. En esa época la discoteca, localizada en una casa payesa de lo que hoy es el Paseo Marítimo de Ibiza (Figura 1), tenía aforo para poco más de 200 personas, 16 trabajadores en total, un tocadiscos y un par de neveras (Diario de Ibiza, 18 de noviembre de 2014). Hoy Pachá Ibiza tiene un aforo de 3.000 personas, genera 1.470 puestos de trabajo entre directos e indirectos y posee la última tecnología en luz y sonido (Figura 2). En 1973 tuvo unos ingresos de aproximadamente $12.000 €$ (Diario de lbiza, 18 de noviembre de 2014), en 2013 de 25,396.000 € (Gráfico 1).

\section{Gráfico 1: Ingresos y Resultados de Pachá Ibiza.}

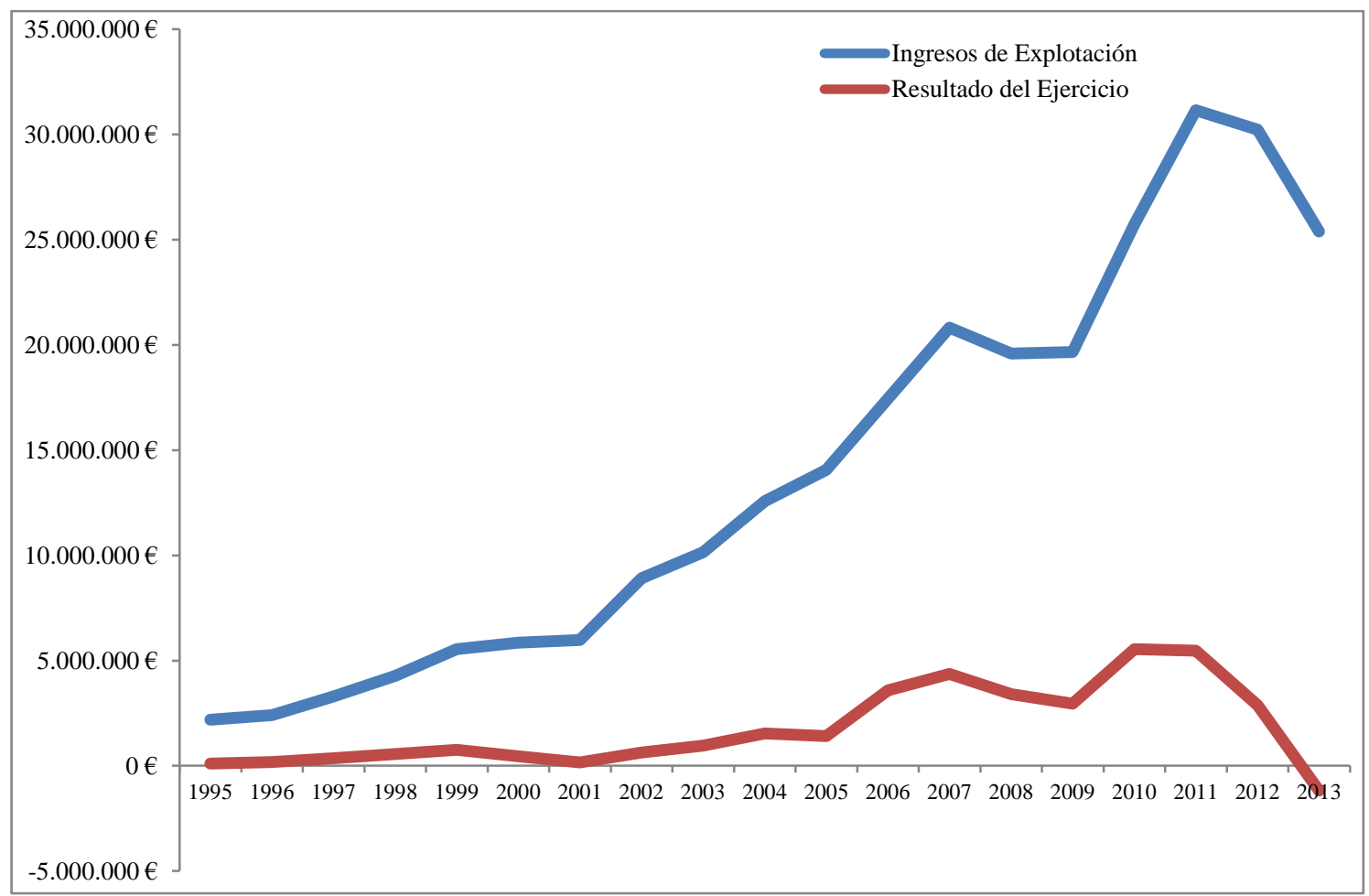

Fuente: SABI y elaboración propia.

REDMARKA UIMA-Universidad de A Coruña - CIECID

Año VIII, Número 15, (2015), v I pp. 101-139

http://www.redmarka.net/ ISSN 1852-2300 
La imagen de Ibiza sería difícil de explicar sin el auge que tuvieron las discotecas en los años ochenta, ayudado también por eventos como el concierto de Bob Marley de 1978. En esos años el sector se expandió en todo el mundo y en Ibiza aún más. Se produjo un incremento del número y las dimensiones de las discotecas ibicencas, espoleado por el auge de los clubs del Reino Unido. Los empresarios de la década anterior ampliaron sus locales e inauguraron nuevos establecimientos, y nuevos empresarios empezaron a aparecer. En todos los casos su mercado principal estaba formado por jóvenes del Reino Unido muy aficionados a la música electrónica.

En los años ochenta Star Club, Éxtasis, Boucala, Glory's, Pachá, Angel's, Playboy, Amnesia y Ku constituían reclamos turísticos de fama mundial y la música disco sustituye al Rock. Destaca la ciudad de lbiza y las zonas cercanas por su oferta. El fotógrafo Derek Ridgers indica:

"Mientras el resto de la isla estaba colonizada por jóvenes británicos de vacaciones, la ciudad de lbiza y las playas y bares adyacentes eran completamente diferentes. Parecía más lujosa y multi-europea, y por la noche las calles y bares alrededor del puerto se transformaban en una versión erótica y vanguardista de lo que estaba ocurriendo en Londres en lugares como Camden Palace, The Batcave, Heaven y The Wag" (Diario de Ibiza, 23 de enero de 2014).

De entre las discotecas destacaba Ku, en Sant Rafel, como referente y símbolo de la oferta nocturna de la isla (Ramón, 2001, p. 158). Esta discoteca empezó como Club San Rafael y en 1978 abrió como Ku lbiza al ser comprada por Javier Iturrioz, Jose Luis Anabitarte "Gorri" y José Antonio Santamaría. Se trataba de una discoteca a cielo abierto con conciertos, concursos y fiestas organizadas por Faruk Gandji, Brasilio Oliviera y Pino Sagliocco. Faruk Gandji recuerda que las fiestas se creaban:

REDMARKA UIMA-Universidad de A Coruña - CIECID

Año VIII, Número 15, (2015), v I pp. 101-139

http://www.redmarka.net/ ISSN 1852-2300 
"Con la intención de recordar a todos que estaban en Ibiza y que gozaban de una libertad casi total.... Las fiestas se organizaban con la colaboración de todo el equipo de Ku.... eran al aire libre, con la luna y las estrellas como techo y el sol amaneciendo tras una noche de éxtasis... Siempre ocurría algo fuera de lo normal gracias a los freaks y criaturas excéntricas de la noche que participaban activamente.... Intentamos divertir a todos en Ibiza: desde los niños, con su fiesta especial los domingos por la tarde, hasta los ancianos, organizando cenas benéficas. Los hippies tenían su fiesta, los gais tenían su fiesta, y hasta los fans de los San Fermines tenían su San Fermín en Ku, con la suelta de una vaquilla y todo" (Ibiza Style, 2013).

Esta discoteca estaba situada cerca del pueblo de Sant Rafael y con acceso directo desde la carretera de Ibiza a Sant Antoni. La grandiosidad de la discoteca y el despliegue de tecnología de luz y sonido, junto a la presencia de grandes estrellas de la música y famosos entre el público (Barón von Thum Taxis, Brigitte Nielsen, Freddie Mercury, Grace Jones, Jean Paul-Gaultier, Johny Weissmuler, Julio Iglesias, Lord Cowdray, Mick Jagger, Niki Lauda, Nina Hagen, Roman Polanski, Ronnie Wood, Steve Strange, Valentino, etc.) hizo que fuera considerada la mejor discoteca del mundo por personas como Faruk Gandji: "las discos de todo el mundo intentaron reproducir lo que aquí sucedía pero no se podía repetir". Derek Ridgers comentaba que:

"La cultura de bailar hasta el amanecer y más allá -after-hours dance- que pegó fuerte primero en la isla -ritmos baleares, éxtasis, superclubes y raves- se convirtió poco más tarde en la gran noticia sobre la cultura juvenil de finales de los ochenta" (Diario de Ibiza, 23 de enero de 2014).

Las molestias causadas a los residentes hicieron que se aprobase normativa para el cierre de las discotecas con la finalidad de reducir ruidos y dos de las más afectadas fueron Ku y Amnesia. La discoteca Ku Ibiza sufrió el hundimiento

REDMARKA UIMA-Universidad de A Coruña - CIECID

Año VIII, Número 15, (2015), v I pp. 101-139

http://www.redmarka.net/ ISSN 1852-2300 
del techo en 1990 y cerró a causa de la crisis a principios de los noventa. En 1995 fue reabierta con el nombre de Privilege y dirigida por José María Etxaniz.

El auge de las discotecas fue tan grande que incluso la Conselleria de Turismo del Govern Balear se sumo a esta moda y lo uso en la promoción turística (Ramón, 2001). Cabe indicar que la forma de hacer las cosas era diferente en los ochenta, como comenta Faruk Gandji:

"Las fiestas de apertura y de clausura eran gratis para todo el mundo.... Algunos artistas o grupos que actuaban en Ku lo hacían a cambio de pasar unas vacaciones en lbiza y no cobraban caché, muchos de ellos estaban tan a gusto que no se querían ir.... A nuestros dj's les mandábamos a Alemania, Bélgica o Inglaterra para buscar canciones inéditas, o muy difíciles de encontrar" (Ibiza Style, 2013).

En los ochenta la organización tenía mucho de improvisación y normalmente no se pedían permisos, como recuerda Faruk Gandji:

"Tú hacías tu fiesta, y si había quejas por ruido, recibías una multa que pagabas, o te las arreglabas para que te la quitasen.... Otras veces nos multaban cuando no se respetaban las horas de cierre, pero por petición popular las fiestas siempre se alargaban hasta el amanecer, así que, al final, compensaba pagar la multa" (Ibiza Style, 2013).

Aunque no sea una discoteca, es necesario mencionar el Hotel Pikes para obtener una visión más completa de la década. En 1978 Anthony Pike compró la finca Ca'n Pep Toniet y la reformó convirtiéndola en un pequeño hotel situado en mitad del campo, cerca de Sant Antoni. Muy pronto el Hotel Pikes obtuvo fama mundial gracias a que en él se filmo el videoclip "Club Tropicana" del grupo Wham!, en 1983, con George Michael como solista. Durante toda la década de los ochenta este establecimiento tuvo gran reputación por las estrellas de la música que lo frecuentaban y el hedonismo que en él se vivía, tanto que preocupó a las autoridades locales por sus excesos. En los noventa

REDMARKA UIMA-Universidad de A Coruña - CIECID

Año VIII, Número 15, (2015), v I pp. 101-139

http://www.redmarka.net/ ISSN 1852-2300 
entró en decadencia, hasta que fue comprado por lbiza Rocks Group en 2008. En 2011 reabrió modernizado pero manteniendo su espíritu como lbiza Rocks House at Pikes Hotel, sirviendo de alojamiento para las estrellas que actúan en Ibiza Rocks. En la actualidad Tony Pike es residente permanente del hotel (El Mundo, 25 de julio de 2013).

Pero los años ochenta tuvieron un lado negativo. La bahía de Sant Antoni de Portmany fue la primera zona en desarrollarse turísticamente (Ramón \& Serra, 2013), pero también la primera en degradarse. Los problemas en la zona del West End de Sant Antoni fue tema recurrente en la prensa: "San Antonio de Portmany. Los gamberros se apoderaron de las calles la noche del domingo" (Diario de Ibiza, 18 de julio de 1978); "La calle de la Virgen, una calle de vandalismo" (Diario de Ibiza, 2 de noviembre de 1979). La conflictividad del West End se achacaba a una falta de efectivos policiales, sobre todo durante la noche, y a los guías de los turoperadores, que conducían a grandes grupos de turistas por una ruta que iba de bar en bar por el West End de Sant Antoni. Algunas personas afirmaban que los guías se sacaban un sobresueldo con las comisiones que recibían de los establecimientos por llevarles grupos de turistas (Ramón, 2001). Esta práctica se conoció en los noventa como pub crawls:

"Los muchachos, al fin y al cabo, van donde los llevan los guías y si éstos los llevan a bares que les pagan una comisión y les hacen un precio especial para emborracharlos, no nos puede extrañar que acaben a las cuatro de la madrugada en cualquier discoteca en un estado de enajenación mental absoluto" (Diario de Ibiza, 13 de agosto de 1989).

A principios de los noventa se produjo una reducción del auge de las discotecas, en parte por los cambios de tendencia y en parte por la crisis general. Tampoco ayudó la necesidad de cierre temporal para realizar las obras necesarias para cubrir las discotecas a cielo abierto y cumplir los nuevos requerimientos normativos. Además, se intentó corregir la imagen de destino turístico de desenfreno y fiesta para no ahuyentar a otros tipos de turismo. A REDMARKA UIMA-Universidad de A Coruña - CIECID

Año VIII, Número 15, (2015), v I pp. 101-139

http://www.redmarka.net/ ISSN 1852-2300 
finales de los noventa hubo un resurgimiento del sector al reabrir diversos locales como Amnesia o Ku (ahora Privilege) y aprovecharse de la tendencia existente en el Reino Unido que facilitó nuevas pautas en el sector, como comentaba Pino Sagliocco:

"En aquella época, Londres experimentaba el boom del underground. Los clubbers tenían serias dificultades para hacer sus fiestas en Inglaterra debido a unas férreas normativas que ponían todo tipo de trabas a fiestas y conciertos. Algunos empresarios del sector pronto vieron en lbiza el lugar perfecto para organizar sus eventos desde Londres. Así comenzaron a planificar viajes relámpago a la isla, con vuelos chárter y paquetes turísticos que incluían viaje, concierto y fiesta. Después, al cabo de un día o dos, regresaban a sus lugares de origen tal y como habían venido. De esta forma, aterrizaron progresivamente nuevas discotecas y toda una serie de grupos que actuaban a su vez como promotores musicales: en Pachá, Ministry of Sound; en Amnesia, Cream y Cocoon; en Privilege, Manumission; en Space, We Love Sundays. $Y$ surgieron nuevas discotecas, como Edén (antigua Star Club), y el emblemático Café del Mar, cuna de la música chill-out. En ese momento, las noches temáticas y los packs turístico-discotequeros convierten lbiza en una party island" (Diario de Ibiza, 21 de agosto de 2013).

Es el turismo clubber, jóvenes británicos llegados exclusivamente atraídos por las fiestas de las grandes discotecas (Ramón, 2001). Vicente de Oteyza indicaba que nada tenía que ver el clubber con el hooligan:

"[Los clubbers] proceden de las clases media o media-alta, exhiben glamur en su vestimenta y en su estilo y son incondicionales adoradores de sus ídolos del techno, el house, el jungla, el trance o el garage. Más que ligar en las discotecas buscan trabar una simple amistad para disfrutar de la música y del baile trepidante" (Diario de Ibiza, 8 de octubre de 2000).

REDMARKA UIMA-Universidad de A Coruña - CIECID

Año VIII, Número 15, (2015), v I pp. 101-139

http://www.redmarka.net/ ISSN 1852-2300 
A parte de las fiestas nocturnas legales, representadas por las discotecas y pequeños clubs nocturnos de la isla, existen las fiestas ilegales o raves. En los años cincuenta y sesenta ya se producían fiestas ilegales en casas de campo, playas y zonas rurales, pero es a partir de los noventa cuando las raves toman grandes dimensiones y ganan en frecuencia. Ernesto Ramón comenta:

"El propio campo se ha convertido en una extensión de las discotecas. Determinados particulares organizan fiestas ilegales en espacios naturales donde está prohibido este tipo de actuaciones. Hasta mil personas llegan a concentrarse en fiestas que duran entre dos y cuatro días. Apartados rincones de la Naturaleza, preferiblemente en la costa virgen, lejos de aglomeraciones urbanas, sirven de escenario para este tipo de actos, donde cientos de automóviles se aparcan en las inmediaciones. Los potentes altavoces crean un ambiente frenético y el clima de las discotecas se traslada así fuera de sus fronteras propias. Sólo en un fin de semana del mes de septiembre de 2000, las fuerzas de seguridad desmantelaban hasta tres fiestas ilegales, pero algunas logran llevarse a cabo" (Ramón, 2001, p. 206).

El hecho de que busquen costas vírgenes para organizar estas fiestas ha hecho que se den con gran abundancia en la costa norte de la isla y que el ayuntamiento de Sant Joan tenga verdaderos problemas para mantener en buen estado su patrimonio natural. Además de las fiestas en las zonas rurales de la isla, otro hecho habitual son los after-hours. Se caracterizan por abrir por la mañana temprano, cuando cierran las discotecas convencionales, y no cierran hasta la tarde o la noche. Las discotecas y todo lo que las rodea tuvo gran impacto mediático, como recoge Manuel Cuellar:

¿¿Por qué lbiza? ¿Qué tiene esta isla mediterránea de 83.000 habitantes que ya estaba de moda hace 30 años para que los mejores creadores se trasladen hasta aquí? ¿Qué posee ese nombre para que se haya convertido en una marca infalible cuando se imprime en la carátula de un REDMARKA UIMA-Universidad de A Coruña - CIECID

Año VIII, Número 15, (2015), v I pp. 101-139

http://www.redmarka.net/ ISSN 1852-2300 
disco? 'Es una mezcla de cosas, Ibiza es una cocina muy sutil en la que influyen muchos ingredientes. Podemos hablar del tópico de la magia, que la hay; pero de cinco años para acá es algo más. Cientos de raves (fiestas) legales e ilegales, música por todas partes y a todas horas, en los locales, la playa, el campo. La gente quiere intercambiar ingredientes que ha traído desde todo el mundo: vivencias, experiencias con las drogas... Todo influye, hasta el viaje que tenga en un momento determinado un $d j$. La mente se abre a nuevas experiencias. La unión de todas esas cosas hace de Ibiza el lugar ideal', explica Mr. Papi frente a un plato de arroz a banda" (El País Semanal, 13 agosto 2000).

En esta época se inició la situación actual: la gestión es mucho más planificada y no queda espacio para la improvisación; la oferta ya no se basa en la interacción de los clientes sino en las performances que preparan los promotores de las fiestas; como indica Pino Sagliocco (Diario de Ibiza, 21 de agosto de 2013) "los djs adquieren un protagonismo sin precedentes y se convierten en las nuevas rock stars" siendo más populares en las redes sociales que las discotecas (Diario de Ibiza, 24 de septiembre de 2013); los precios se disparan y el tratamiento VIP aparece vinculado a precios desorbitados por la entrada, y se popularizan nuevas formas de oferta como los beach club (Bora Bora, Café del Mar, etc.), los hotel club (lbiza Rocks) y los party boat. En esta nueva época, según Pino Sagliocco:

"las discotecas vuelven a ser rentables y se convierten en un gran negocio y una importante fuente de ingresos para la isla. Es el boom de los dj's y de las sesiones que recorrerán el mundo entero, siendo lbiza el principal referente de esta industria. Cada propuesta clubber forma su propia tribu; los jóvenes se suman a esta nueva idea de clan musical" (Diario de Ibiza, 21 de agosto de 2013).

REDMARKA UIMA-Universidad de A Coruña - CIECID

Año VIII, Número 15, (2015), v I pp. 101-139

http://www.redmarka.net/ ISSN 1852-2300 
Figura 3: Las siete grandes de principios del siglo XXI.

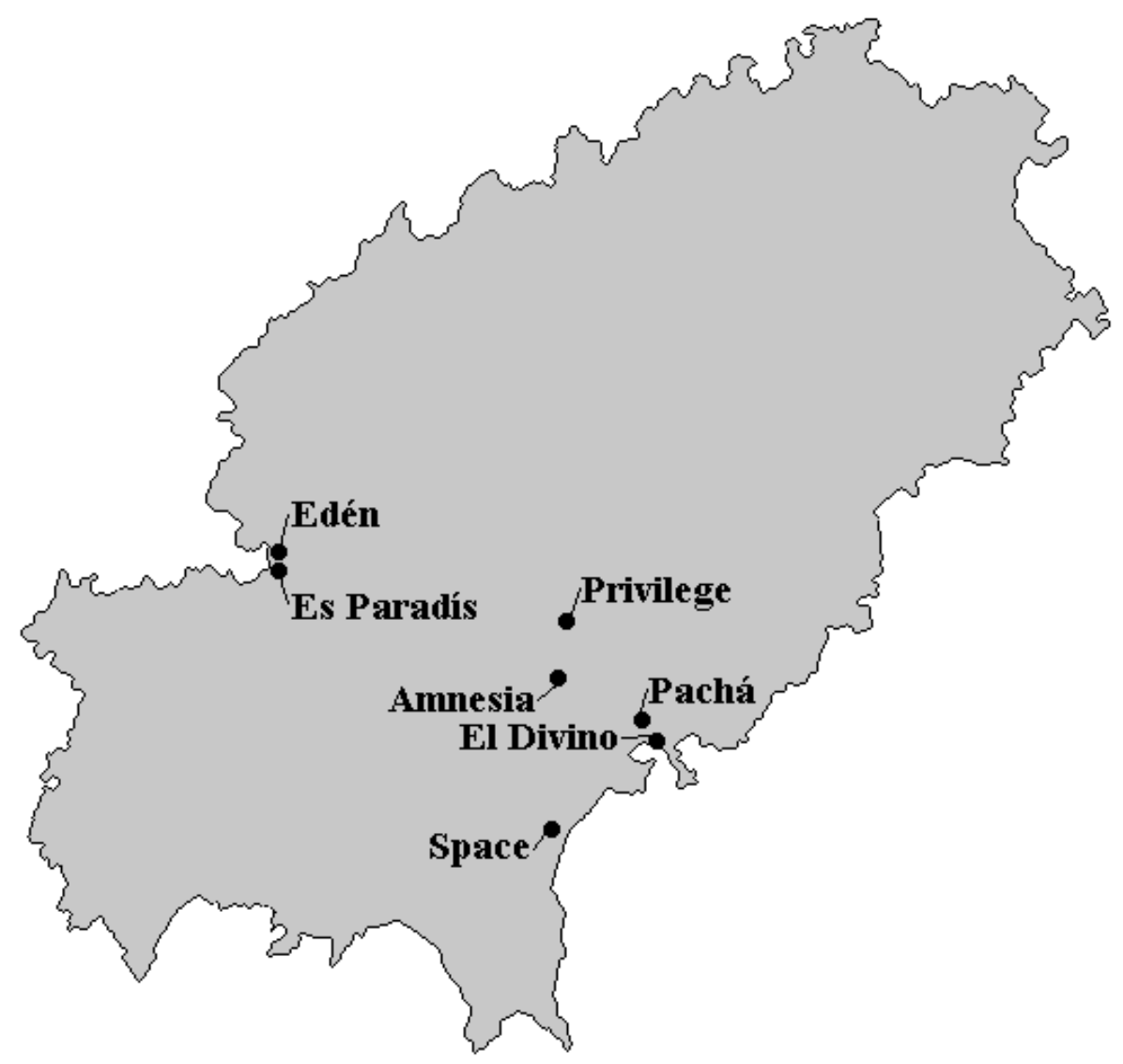

Fuente: elaboración propia.

Entre finales de los noventa y el inicio del nuevo siglo se forma un grupo de siete discotecas que son la imagen de Ibiza en el mundo y acaparan el protagonismo (Figura 3):

- Es Paradís fue creada en 1975 en Sant Antoni por Pepe Aguirre y Lluís Güell, siendo famosa por la Fiesta del Agua.

- Edén (antes Star Club) es la otra gran discoteca de Sant Antoni y en la actualidad ha vivido diversos cambios de propiedad y de nombre.

- Amnesia tiene sus orígenes en una casa de campo de la carretera de lbiza a Sant Antoni que fue comprada por Antonio Escohotado en 1976 y, tras cambios de propiedad y altibajos, en la actualidad es propiedad de Martín

REDMARKA UIMA-Universidad de A Coruña - CIECID

Año VIII, Número 15, (2015), v I pp. 101-139

http://www.redmarka.net/ ISSN 1852-2300 
Ferrer y una de las principales de la isla. Amnesia posee la patente tecnológica de Xpanded Amnesia Technology.

- Privilege está situada cerca de Amnesia y del pueblo de Sant Rafel, siendo en la actualidad una de las más importantes aunque sin la relevancia de Amnesia, Pachá o Space.

- Pachá lbiza es la decana del sector y el buque insignia de una gran multinacional bajo la marca Pachá con diversos establecimientos en Ibiza y Sitges, además de una veintena de franquicias (algunas de gran prestigio internacional como Pachá New York o Pachá Sharm El Sheik).

- El Divino, situada en Marina Ibiza, era la más pequeña de las siete por tratarse en su origen de un club privado abierto en 1992. El Divino fue comprado por el Grupo Pachá y reabierto el local como restaurante Cabaret Lío.

- Space abrió en 1989 y es propiedad de Pepe Roselló, siendo famosa durante muchos años por abrir 22 horas al día hasta que los cambios en la normativa municipal lo impidieron.

Con el nuevo siglo se han intentado diversas iniciativas de colaboración dentro del sector. En 2003 se creó la Asociación de Discotecas de Ibiza (ADI), de la que formaban parte las discotecas Amnesia, Edén, El Divino, Es Paradís, Pachá, Privilege y Space (las siete grandes). El primer presidente fue Ricardo Urgell, propietario y fundador del grupo Pachá, pero en 2006 la asociación fue disuelta tras ser abandonada por Es Paradís y Pachá.

En 2009 se promovió desde las administraciones locales, principalmente el Consell Insular, la creación de un Clúster Tecnológico denominado Ibiza Music Island, con el objetivo de que la isla se convirtiera en el mejor distrito internacional para la innovación musical. La gestión correspondía a la Agrupación Empresarial Innovadora y se pretendía alcanzar el objetivo propuesto mediante la puesta en contacto de empresas, creadores, científicos, desarrolladores y administraciones (Diario de Ibiza, 29 de mayo de 2009). El

REDMARKA UIMA-Universidad de A Coruña - CIECID

Año VIII, Número 15, (2015), v I pp. 101-139

http://www.redmarka.net/ ISSN 1852-2300 
Clúster Tecnológico fue certificado como Proyecto Excelente, Prioritario e Integrado en el Programa Nacional de Redes del Plan Nacional de Investigación Científica, Desarrollo e Innovación Tecnológica 2008-2011 del Ministerio de Industria, Turismo y Comercio. Por desgracia, este proyecto quedó reducido a varias reuniones de políticos locales y a una mesa con un administrativo, y tras las elecciones locales y autonómicas de 2011 desapareció.

\section{SITUACIÓN ACTUAL DEL SECTOR EN IBIZA}

Figura 4: Localización de los establecimientos más importantes.

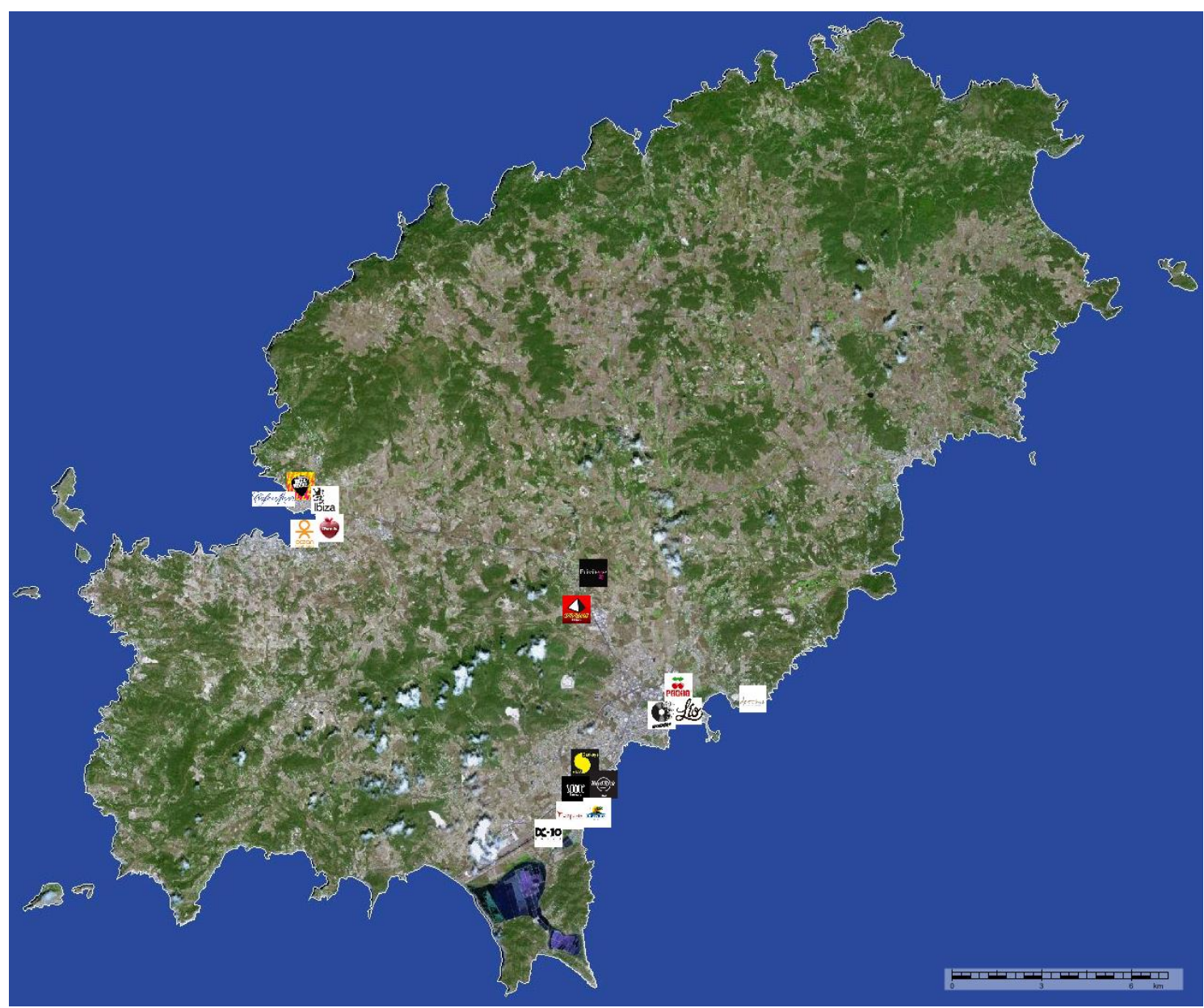

Fuente: Google Earth y elaboración propia.

REDMARKA UIMA-Universidad de A Coruña - CIECID

Año VIII, Número 15, (2015), v I pp. 101-139

http://www.redmarka.net/ ISSN 1852-2300 
En la actualidad, la imagen mundial de Ibiza como destino de ocio nocturno se sustenta en una oferta compuesta por un grupo de grandes establecimientos (Figura 4) complementado por pequeñas discotecas, bares y pubs con unas características distintivas que han conllevado la aparición de un estilo propio de la isla. Una de las características de los establecimientos nocturnos es la presencia de dj's, incluso en pequeños establecimientos de pueblos del interior. Todos los veranos unos 300 o 400 dj's trabajan en Ibiza. Entre estos dj's se encuentran los mejores del panorama mundial del momento y trabajar en la isla se convierte en una magnifica línea para el currículum de estos profesionales. Cabe indicar que las grandes discotecas ofrecen distintas fiestas en distintos días de la semana, ofreciendo un calendario de fiestas como el que se muestra en la Tabla 1. Estas fiestas son de por si productos diferenciados que en algunos casos poseen sus propias líneas de productos promocionales y tiendas, como es el caso de $F^{* * *} M e$ l'm Famous y Matinée.

Tabla 1: Oferta de fiestas en el verano de 2014

\begin{tabular}{|c|c|c|c|c|c|c|c|}
\hline & Lunes & Martes & Miércoles & Jueves & Viernes & Sábado & Domingo \\
\hline Space & Café Olé & $\begin{array}{l}\text { Carl Cox - } \\
\text { Music Is } \\
\text { Revolution }\end{array}$ & Ibiza Calling & ENTER. & $\begin{array}{l}\text { Clandestin } \\
\text { Presents } \\
\text { FULL ON } \\
\text { Ibiza }\end{array}$ & $\begin{array}{l}\text { Kehakuma } \\
\text { Elrow Ibiza }\end{array}$ & We Love \\
\hline Amnesia & Cocoon Ibiza & Together & $\begin{array}{c}\text { La Troya } \\
\text { Foam Party }\end{array}$ & Cream Ibiza & Music On & Matinée & $\begin{array}{l}\text { Amnesia } \\
\text { Presents }\end{array}$ \\
\hline Privilege & Neon Splash & Sunk & Reverse & Mass Bass & SuperMartXé & The Pharm & \\
\hline Pacha & $\begin{array}{c}\text { Ibiza Rocks } \\
\text { House }\end{array}$ & $\begin{array}{l}\text { Flower } \\
\text { Power }\end{array}$ & $\begin{array}{c}\text { Aoki's } \\
\text { Playhouse }\end{array}$ & $\begin{array}{l}\mathrm{F}^{* * *} \text { Me I'm } \\
\text { Famous }\end{array}$ & Insane & Pure Pacha & Solomun +1 \\
\hline Gatecrasher & Crasher & Créche lbiza & Bedlam & Speakerbox & El Carnaval & Kisstory & $\begin{array}{c}\text { Gatecrasher } \\
\text { Presents }\end{array}$ \\
\hline Es Paradís & So Funked & $\begin{array}{c}\text { Fiesta del } \\
\text { Agua }\end{array}$ & $\begin{array}{c}\text { Ibiza Rocks } \\
\text { After Party }\end{array}$ & & $\begin{array}{l}\text { Fiesta del } \\
\text { Agua } \\
\text { Judgement } \\
\text { Fridays }\end{array}$ & Hed Kandi & $\begin{array}{c}\text { GLOW Neon } \\
\text { Paint Party }\end{array}$ \\
\hline
\end{tabular}

REDMARKA UIMA-Universidad de A Coruña - CIECID

Año VIII, Número 15, (2015), v I pp. 101-139

http://www.redmarka.net/ ISSN 1852-2300 


\begin{tabular}{|c|c|c|c|c|c|c|c|}
\hline Sankeys & $\begin{array}{c}\text { Duke } \\
\text { Dumont } \\
\text { Presents } \\
\text { Blasé Boys } \\
\text { Club } \\
\end{array}$ & FUSE & $\begin{array}{c}\text { Tribal } \\
\text { Sessions }\end{array}$ & Cuff & Flying Circus & $\begin{array}{c}\text { Magna Carta } \\
\text { ADELANTE }\end{array}$ & $\begin{array}{c}\text { Viva } \\
\text { Warriors }\end{array}$ \\
\hline $\begin{array}{l}\text { Benimussa } \\
\text { Park }\end{array}$ & & & Channel Zoo & & & $\begin{array}{l}\text { The Zoo } \\
\text { Project }\end{array}$ & The Quarry \\
\hline Booom & $\begin{array}{c}\text { Toolroom } \\
\text { Knights Ibiza }\end{array}$ & $\begin{array}{l}\text { Defected In } \\
\text { The House }\end{array}$ & Suara & & $\begin{array}{c}\text { Phantasmag } \\
\text { oria }\end{array}$ & Glitterbox & $\begin{array}{l}\text { The Love } \\
\text { Club }\end{array}$ \\
\hline DC-10 & Circo Loco & & Paradise & & & $\begin{array}{l}\text { Movement } \\
\text { Ibiza }\end{array}$ & \\
\hline Destino & & & & $\begin{array}{c}\text { Diynamic } \\
\text { Outdoor o } \\
\text { Luciano \& } \\
\text { Friends }\end{array}$ & & & \\
\hline Hard Rock & & & & & $\begin{array}{l}\text { This Is Hard } \\
\text { Rock Hotel }\end{array}$ & & \\
\hline Ibiza Rocks & & & Ibiza Rocks & & W.A.R.! & & \\
\hline Ushuaïa & David Guetta & $\begin{array}{c}\text { I Am } \\
\text { Hardwell }\end{array}$ & Departures & $\begin{array}{c}\text { Armin Van } \\
\text { Buuren Pres. } \\
\text { A State Of } \\
\text { Trance }\end{array}$ & & ANTS & $\begin{array}{c}\text { Avicii } \\
0 \\
\text { La Familia }\end{array}$ \\
\hline
\end{tabular}

Fuente: elaboración propia.

La importancia mundial de las discotecas de lbiza se puede observar en diversas referencias del sector. Dentro de los Annual International Dance Music Awards, que son parte de la Miami Winter Music Conference, se crearon en 2005 las categorías Best Global Club y Best US Club. En la categoría Best Global Club (Tabla 2), Ibiza suele tener tres o cuatro de las siete nominaciones y han sido nominadas siempre Amnesia y Space. De once ediciones, han ganado en diez ocasiones establecimientos de la isla: cinco veces la discoteca Space, cuatro veces la discoteca Amnesia y una el hotel club Ushuaïa.

Tabla 2: Categoría Best Global Club de los AIDMA.

\begin{tabular}{lccccccccccc}
\hline NIGHTCLUB & 2005 & 2006 & 2007 & 2008 & 2009 & 2010 & 2011 & 2012 & 2013 & 2014 & 2015 \\
\hline Amnesia (Ibiza) & Nom. & Nom. & Gana & Gana & Gana & Nom. & Gana & Nom. & Nom. & Nom. & Nom. \\
\hline Berghain (Berlín) & & & & & & & Nom. & & Nom. & Nom. & Nom. \\
\hline CocoonClub (Frankfurt) & & \multicolumn{1}{c}{ Nom. } & & & & & & & & Nom. \\
\hline DC-10 (Ibiza) & & & & & & & & & &
\end{tabular}

REDMARKA UIMA-Universidad de A Coruña - CIECID

Año VIII, Número 15, (2015), v I pp. 101-139

http://www.redmarka.net/ ISSN 1852-2300 


\begin{tabular}{|c|c|c|c|c|c|c|c|c|c|c|c|}
\hline Fabric (Londres) & Nom. & & Nom. & & & Nom. & Nom. & Nom. & & Nom. & Nom. \\
\hline Godskitchen (Londres) & Nom. & & & & & & & & & & \\
\hline Green Valley (Camboriú) & & & & & & Nom. & & & & & \\
\hline $\begin{array}{l}\text { Ministry of Sound } \\
\text { (Londres) }\end{array}$ & Nom. & Nom. & & & Nom. & Gana & Nom. & Nom. & Nom. & Nom. & Nom. \\
\hline Pachá (Ibiza) & Nom. & Nom. & Nom. & Nom. & Nom. & Nom. & Nom. & Nom. & Nom. & & Nom. \\
\hline Pachá (Londres) & & & Nom. & & & & & & & & \\
\hline Privilege (Ibiza) & & & & & & & Nom. & & Nom. & Nom. & \\
\hline Space (Ibiza) & Gana & Gana & Nom. & Nom. & Nom. & Nom. & Nom. & Gana & Gana & Gana & Nom. \\
\hline Stereo (Montreal) & & & & Nom. & & & & & & & \\
\hline $\begin{array}{l}\text { The Guvernment } \\
\text { (Toronto) }\end{array}$ & & & & Nom. & Nom. & Nom. & Nom. & Nom. & Nom. & & \\
\hline Ushuaïa (Ibiza) & & & & & & & & & & & Gana \\
\hline Zouk (Singapur) & & & & & & & & Nom. & Nom. & & \\
\hline
\end{tabular}

\section{Fuente: Web site Winter Music Conference.}

La revista DJMag, referente del sector, publica anualmente rankings de las cien mejores discotecas según votación de sus lectores. De las 40 primeras de 2014 (Tabla 3), siete son de Ibiza (Space, Pacha, Amnesia, Ushuaïa, DC-10, Sankeys y Privilege). Vemos por tanto que las grandes discotecas de lbiza son de las primeras del mundo tanto si son valoradas por profesionales (Miami Winter Music Conference) como por aficionados en general (DJMag).

Tabla 3: Los 40 primeros clubs del Top 100 Clubs de DjMag.

\begin{tabular}{ccccccclllr}
\hline 2008 & $\mathbf{2 0 0 9}$ & $\mathbf{2 0 1 0}$ & $\mathbf{2 0 1 1}$ & $\mathbf{2 0 1 2}$ & $\mathbf{2 0 1 3}$ & $\mathbf{2 0 1 4}$ & NIGHTCLUB & CIUDAD & PAÍs & AFORO \\
\hline $\mathbf{2}$ & $\mathbf{3}$ & $\mathbf{7}$ & $\mathbf{1}$ & $\mathbf{1}$ & $\mathbf{2}$ & $\mathbf{1}$ & Space & lbiza & España & $\mathbf{7 . 0 0 0}$ \\
\hline- & - & 27 & 3 & 2 & 1 & $\mathbf{2}$ & Green Valley & Camboriu & Brasil & 6.000 \\
\hline $\mathbf{7}$ & $\mathbf{7}$ & $\mathbf{5}$ & $\mathbf{5}$ & $\mathbf{2}$ & $\mathbf{3}$ & $\mathbf{3}$ & Pacha & Ibiza & España & $\mathbf{3 . 0 0 0}$ \\
\hline $\mathbf{1}$ & 2 & 2 & 13 & $\mathbf{8}$ & 4 & 4 & Fabric & Londres & R. Unido & 1.600 \\
\hline- & - & - & 11 & 7 & 6 & 5 & BCM & Mallorca & España & 3.000 \\
\hline $\mathbf{3}$ & $\mathbf{5}$ & $\mathbf{3}$ & $\mathbf{4}$ & $\mathbf{9}$ & $\mathbf{1 0}$ & $\mathbf{6}$ & Amnesia & Ibiza & España & $\mathbf{5 . 0 0 0}$ \\
\hline 11 & 13 & 10 & 9 & 5 & 5 & 7 & Zouk & Singapur & Singapur & 3.000 \\
\hline 21 & 19 & 35 & 14 & 10 & 8 & $\mathbf{8}$ & Sirena & Sào Sebastiào & Brasil & 5.000 \\
\hline- & - & - & - & 97 & 12 & 9 & Octagon & Seúl & R. Corea & 2.500 \\
\hline- & - & - & - & - & - & 10 & Hakkasan & Las Vegas & E.E.U.U. & 3.024 \\
\hline- & - & - & - & $\mathbf{6 7}$ & $\mathbf{2 8}$ & $\mathbf{1 1}$ & Ushuaïa & lbiza & España & $\mathbf{5 . 0 0 0}$ \\
\hline 23 & 6 & 4 & 8 & 6 & 7 & 12 & Ministry of Sound & Londres & R. Unido & 1.500 \\
\hline
\end{tabular}

REDMARKA UIMA-Universidad de A Coruña - CIECID

Año VIII, Número 15, (2015), v I pp. 101-139

http://www.redmarka.net/ ISSN 1852-2300 


\begin{tabular}{|c|c|c|c|c|c|c|c|c|c|c|}
\hline- & - & 50 & 22 & 20 & 15 & 13 & Guaba Beach Bar & Limassol & Chipre & 2.500 \\
\hline 20 & 1 & 8 & 6 & 13 & 18 & 14 & Berghain & Berlín & Alemania & 1.500 \\
\hline- & - & - & 80 & 11 & 11 & 15 & Marquee & Las Vegas & E.E.U.U. & 3.000 \\
\hline 14 & 17 & - & 17 & 16 & 14 & 16 & DC-10 & Ibiza & España & 1.500 \\
\hline 9 & 15 & 20 & 26 & 38 & 16 & 17 & Warung Beach Club & Camboriu & Brasil & 2.500 \\
\hline 76 & - & - & 46 & 39 & 27 & 18 & Cocorico & Rímini & Italia & 6.000 \\
\hline- & - & - & - & - & 38 & 19 & Echostage & Washington DC & E.E.U.U. & 3.000 \\
\hline- & - & - & 67 & 60 & 33 & 20 & Paradise Club & Mykonos & Grecia & 5.000 \\
\hline 72 & 51 & 69 & - & 28 & 23 & 21 & Anzu & Sao Paulo & Brasil & 3.000 \\
\hline 35 & 44 & 11 & 2 & 4 & 9 & 22 & Fabrik & Madrid & España & 10.000 \\
\hline- & - & - & 32 & 30 & 25 & 23 & Papaya & Pag & Croacia & 4.500 \\
\hline 47 & 43 & 12 & 10 & 15 & 13 & 24 & Cavo Paradiso & Mykonos & Grecia & 2.800 \\
\hline- & 95 & 62 & 19 & 12 & 20 & 25 & Yalta & Sofía & Bulgaria & 1.000 \\
\hline- & - & 9 & 55 & - & 19 & 26 & Warehourse Project & Manchester & R. Unido & 5.000 \\
\hline- & - & - & 61 & 43 & 35 & 27 & Trouw & Ámsterdam & Holanda & 1.100 \\
\hline- & - & - & - & - & 80 & 28 & Sankeys & Ibiza & España & 1.500 \\
\hline- & 87 & - & 92 & 37 & 31 & 29 & Motion & Bristol & R. Unido & 1.450 \\
\hline- & - & - & - & 81 & 53 & 30 & Air & Ámsterdam & Holanda & 1.300 \\
\hline 24 & 30 & 37 & 27 & 18 & 26 & 31 & Pacha & New York & E.E.U.U. & 2.400 \\
\hline- & - & - & - & - & 48 & 32 & Bootshaus & Colonia & Alemania & 1.200 \\
\hline 43 & 49 & 36 & 16 & 14 & 17 & 33 & Privilege & Ibiza & España & 10.000 \\
\hline- & - & - & - & - & 30 & 34 & Venue & Athenas & Grecia & 1.500 \\
\hline- & - & - & - & - & 50 & 35 & Miroir & Rio de Janeiro & Brasil & 600 \\
\hline- & - & - & - & 69 & 41 & 36 & Space & Sharm El Sheik & Egipto & 5.000 \\
\hline- & - & - & 91 & 33 & 34 & 37 & Surrender/Encore & Las Vegas & E.E.U.U. & 3.000 \\
\hline 8 & 12 & 31 & 18 & 27 & 22 & 38 & The Guvernment & Toronto & Canadá & 5.000 \\
\hline- & - & - & - & - & - & 39 & Sky Room & Ribeirao Preto & Brasil & 700 \\
\hline 82 & 40 & 73 & 95 & 58 & 49 & 40 & Avalon & Los Ángeles & E.E.U.U. & 1.500 \\
\hline
\end{tabular}

Fuente: Web site DjMag.

En la actualidad los establecimientos de ocio nocturno de Ibiza lideran tanto en el mundo real como en las redes sociales (Diario de Ibiza, 24 de septiembre de 2013), pero la enorme sofisticación y tecnificación del sector hace que este liderazgo no impida cierta añoranza entre los veteranos del sector. Por ejemplo, Ricardo Urgell recuerda que "cuando yo empecé solo necesitaba una agenda y era perfecto. No había ni teléfono. Por no haber no había ni agua corriente, la traíamos con camiones. Lo cambiaba todo ahora mismo por aquello" (Diario de Ibiza, 18 de noviembre de 2014). Por su parte, Pino Sagliocco comentaba:

REDMARKA UIMA-Universidad de A Coruña - CIECID

Año VIII, Número 15, (2015), v I pp. 101-139

http://www.redmarka.net/ ISSN 1852-2300 
"Lo que antes era diversión ahora es estrés, con dispositivos de seguridad y listas VIP... Lo que antes era mezcla, convivencia y libertad, ahora es agobio y asfixia. Creo sin duda que el concepto de VIP hizo que la realidad de la isla se alterara de forma brutal, salvaje. Antes todos éramos VIP, y los verdaderos VIPs que se hallaban en Ibiza se integraban y transmitían alegría y diversión, eran admirados y un honor poder disfrutar de ellos" (Diario de Ibiza, 21 de agosto de 2013).

Se trata de un sector que sufre muchos fracasos empresariales debido a la complejidad de trabajar con un producto tan incontrolable como las interacciones entre personas y a una falta de seriedad del empresariado, como comenta Ricardo Urgell:

"Normalmente, el que monta una discoteca es uno que no sabe qué hacer con su vida o uno que tiene un local y no sabe qué hacer con él, el carnicero que tiene mucho dinero y quiere conocer a gente, el que cree que teniendo una discoteca ligará mucho, el que tiene un hijo y no sabe qué hacer con él o el que tiene una novia y la quiere lucir. Todo esto fracasa, solo triunfa el que se lo toma en serio" (Diario de Ibiza, 18 de noviembre de 2014).

La rutina tipo de los turistas clubber a lo largo del día (Figura 5) marca la especialización de los establecimientos y zonas a la vez que determina que zonas y a qué hora se encuentran las más destacadas actividades de ocio nocturno:

- Descanso. Los turistas que visitan la isla por la oferta de ocio nocturno suelen dedicar las mañanas a descansar, salvo algunos casos en que se continúa la fiesta en algún establecimiento que de forma legal o no ofrece una oferta de tipo After Hours. Hay distintos niveles adquisitivos dentro del turismo clubber y también se plasma en los alojamientos. En los últimos años ha aumentado la oferta de hoteles de categoría alta (cuatro y cinco

REDMARKA UIMA-Universidad de A Coruña - CIECID

Año VIII, Número 15, (2015), v I pp. 101-139

http://www.redmarka.net/ ISSN 1852-2300 
estrellas) y los alojamientos en viviendas, principalmente chalets en el campo.

Figura 5: Esquema de la rutina diaria ideal del turista Clubber.

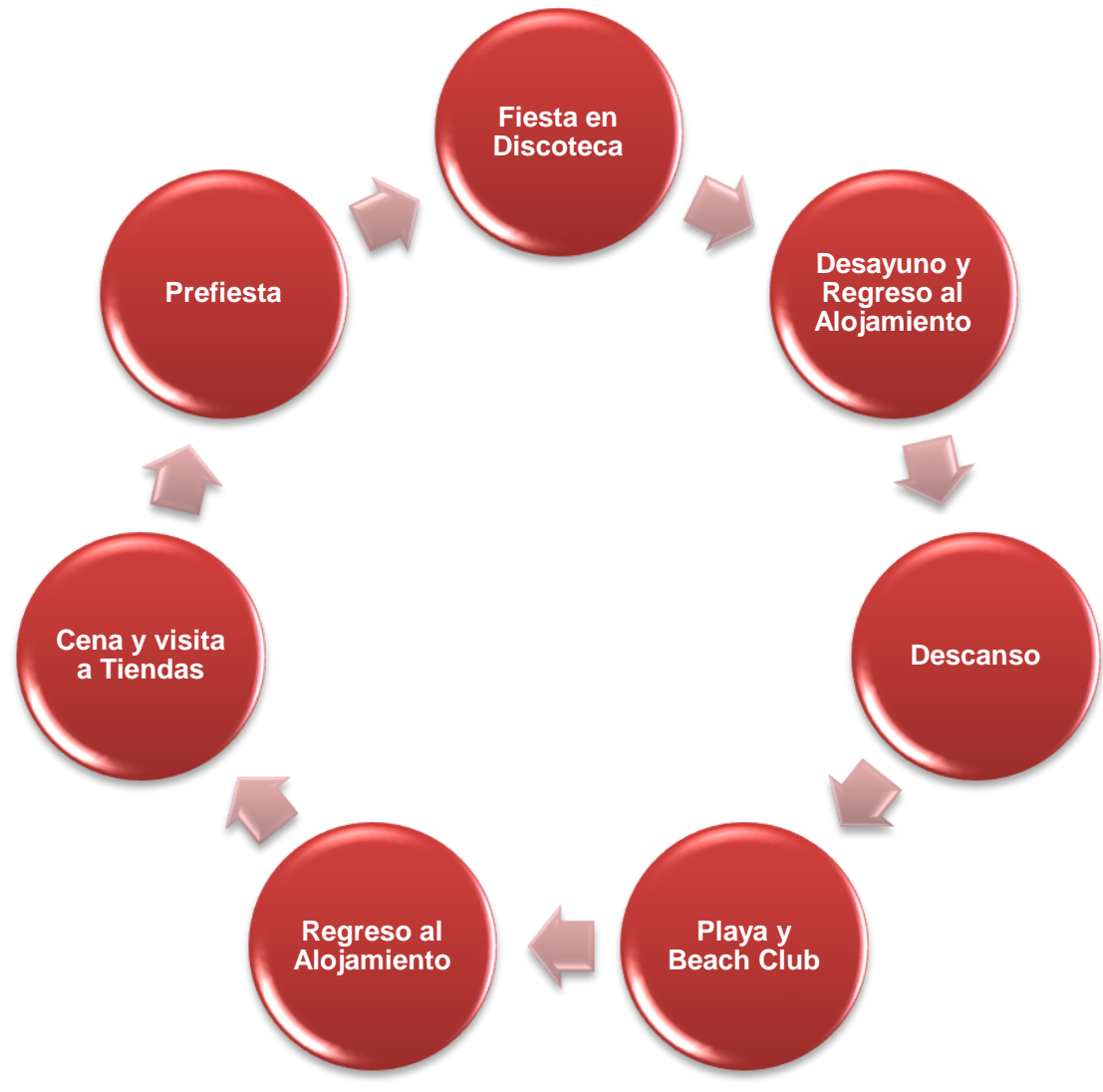

Fuente: elaboración propia.

- Playa y Beach Club. Tras descansar se produce el desplazamiento hacia las playas y calas de la isla a partir de media mañana. Según el poder adquisitivo se viaja en transporte público, coche o motocicleta de alquiler, o en embarcaciones de distintos tamaños. La playa más popular de todas es Illetes en Formentera, pero la situación es parecida en el resto de playas. Suele comerse en los establecimientos de las playas que han evolucionado desde el típico chiringuito hacia el concepto de beach club,

REDMARKA UIMA-Universidad de A Coruña - CIECID

Año VIII, Número 15, (2015), v I pp. 101-139

http://www.redmarka.net/ ISSN 1852-2300 
principalmente en la bahía de Sant Antoni y playa d'en Bossa. Al atardecer aumenta la actividad en los beach club, destacando en Sant Antoni el momento de la puesta de sol.

- Regreso al Alojamiento. Normalmente tras el regreso de la playa y antes de iniciar las actividades nocturnas se pasa por el hotel o la casa alquilada para descansar y preparar la noche.

- Cena y visita a Tiendas. Con el anochecer se inician las actividades propiamente de ocio nocturno. Las primeras actividades de la noche son visitar tiendas y cenar. En el barrio de la Marina, en la ciudad de Ibiza, es donde hay más tradición y las horas de mayor afluencia de turistas son entre la puesta de sol y la media noche, permaneciendo abiertos los locales (restaurantes y tiendas) hasta la media noche o más. Aunque la Marina es la zona con más tradición, entre el turismo con mayor poder adquisitivo destaca el Paseo Marítimo de Ibiza o el pueblo de Sant Rafel y entre el turismo británico con menor poder adquisitivo Sant Antoni.

- Prefiesta. La prefiesta engloba las ofertas musicales que van de la puesta del sol a la media noche o las dos o tres de la madrugada. Es el momento álgido del día para los bares de copas de la Marina o Sant Rafel y los hotel club (Ibiza Rocks Hotel, Ushuaïa Ibiza Beach Hotel, Hard Rock Hotel Ibiza, Destino Pacha Ibiza Resort, etc.). También poseen mucha actividad los beach club de Sant Antoni (Café del Mar, Café Mambo, etc.) y playa d'en Bossa (Bora Bora, Nassau, etc.). El hecho de que muchos de estos establecimientos sean a cielo abierto o con importantes terrazas limita la música más allá de la media noche. En los establecimientos tipo lounge con música chill-out o similar puede prolongarse más tiempo la actividad y tras abandonar el establecimiento sus clientes suelen dirigirse directamente a sus alojamientos para descansar.

- Fiesta en Discoteca. En las playas de moda (Ses Salines y Playa d'en Bossa) y las zonas de copas de la ciudad de Ibiza son tradicionales los pasacalles (Figura 6) que promocionan las fiestas de esa noche en las REDMARKA UIMA-Universidad de A Coruña - CIECID

Año VIII, Número 15, (2015), v I pp. 101-139

http://www.redmarka.net/ ISSN 1852-2300 
grandes discotecas con la intención de captar clientes. Estas fiestas se inician pasada la media noche y se prolongan hasta las siete $u$ ocho de la mañana, en que se produce el cierre de la discoteca. Es el producto principal de la oferta clubber y los precios de las entradas y de las consumiciones son muy elevados en comparación con otras partes del mundo, consecuencia de la relevancia mundial de las mismas, y comparados con los años ochenta.

Figura 6: Pasacalles de la "Flower Power" de Pachá (2013).

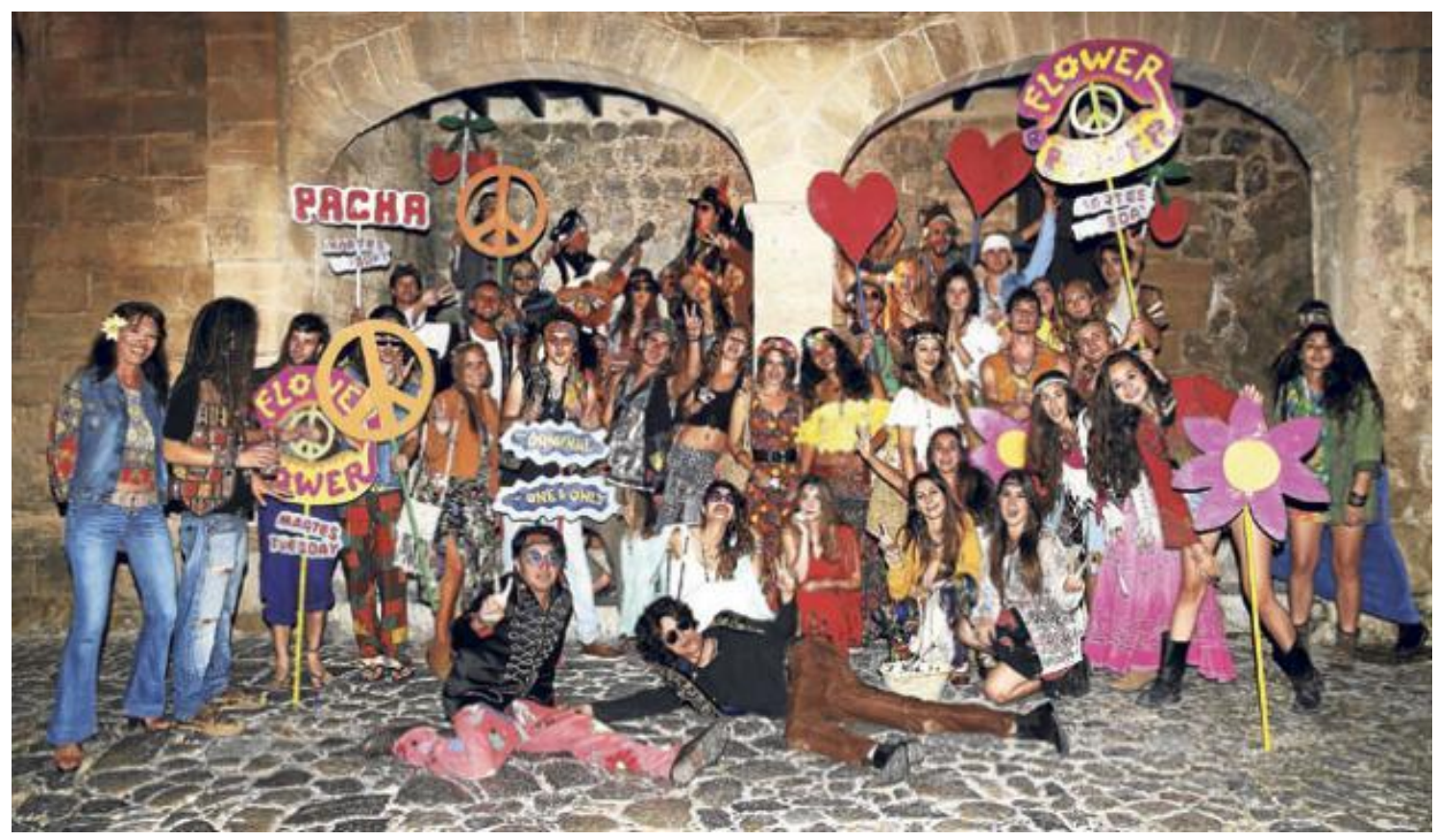

Fuente: Diario de Ibiza.

- Desayuno y Regreso al Alojamiento. Tras el cierre de las discotecas es bastante habitual aprovechar para comer algo en los bares y cafeterías que abren a esa hora antes de regresar al hotel para descansar.

Esta rutina del turismo clubber implica un importante desembolso económico haciendo que este turismo sea económicamente mejor de lo que muchas

REDMARKA UIMA-Universidad de A Coruña - CIECID

Año VIII, Número 15, (2015), v I pp. 101-139

http://www.redmarka.net/ ISSN 1852-2300 
personas creen. El inconveniente es que se trata de un turismo que causa molestias en las zonas cercanas (ruido y tráfico), y en Sant Antoni hay un tipo de turismo problemático y con un nivel adquisitivo bajo. Cabe indicar que las acciones de las administraciones pueden generar importantes impactos en la actividad de unos establecimientos cuya oferta se fundamenta en una gran libertad de acción.

\section{CONCLUSIONES}

El éxito del sector se fundamenta en empresarios y establecimientos con una larga trayectoria, que en algunos casos se remonta a los años setenta como Pachá, Amnesia, Privilege y Es Paradís, una importante política de reinversión de los grandes establecimientos y una importante capacidad de innovación (Figura 7), ejemplificada en los beach clubs, los hotel clubs o la patente Xpanded Amnesia Technology. Todo ello ha convertido a los grandes establecimientos de la isla (Amnesia, DC-10, Es Paradis, Pachá, Privilege, Sankeys, Space, Ushuaïa) en referente para las discotecas y los dj's de todo el mundo.

Figura 7: Ushuaïa lbiza Beach Hotel.

REDMARKA UIMA-Universidad de A Coruña - CIECID

Año VIII, Número 15, (2015), v I pp. 101-139

http://www.redmarka.net/ ISSN 1852-2300 


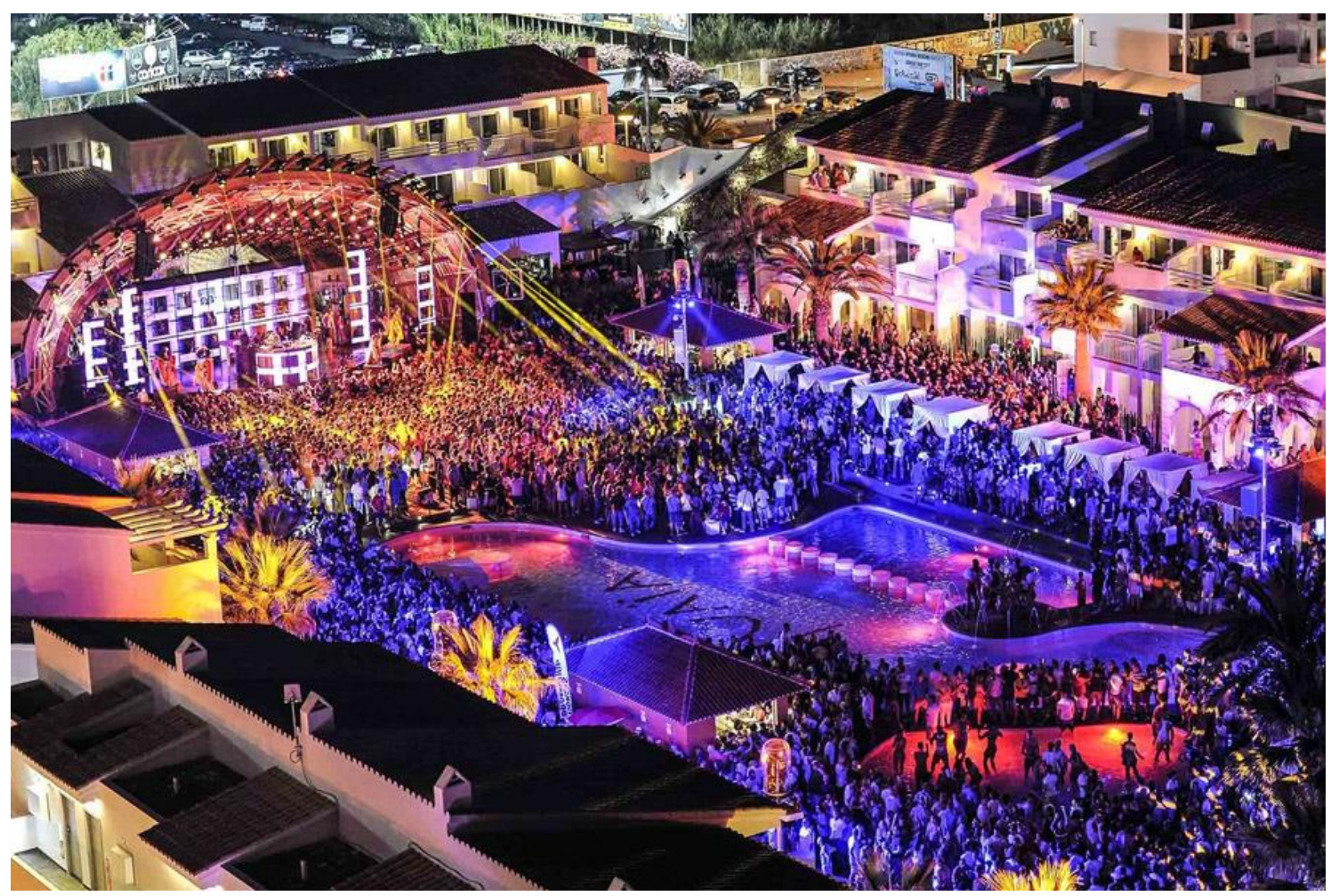

Fuente: Web site Turismo Ibiza

El gran inconveniente del sector es que es una actividad polémica y con problemas de imagen entre los residentes, por las molestias que genera en las cercanías de los establecimientos (ruidos y tráfico) y por los peligros en forma de malas influencias sociales que pueden conllevar (drogas, alcohol, promiscuidad, etc.). Pero no es el único problema del sector:

- Los empresarios del sector tienen importantes desavenencias que dificultan la colaboración, como demostró el fracaso de la Asociación de Discotecas de Ibiza (ADI), aunque actualmente existe un nuevo intento con la Asociación Ocio de Ibiza (Amnesia, Blue Marlin, Bora Bora, DC-10, Km.5, Nassau, Privilege y Ushuaïa). Ello ha llevado a que las relaciones dentro del sector hayan pasado de un cierto respeto en los ochenta a una situación de casi enfrentamiento en la actualidad, especialmente entre los distintos tipos de establecimientos (Discotecas vs. Beach Clubs y Hotel

REDMARKA UIMA-Universidad de A Coruña - CIECID

Año VIII, Número 15, (2015), v I pp. 101-139

http://www.redmarka.net/ ISSN 1852-2300 
Clubs) por supuesta competencia desleal (Diario de Ibiza, 13 de septiembre de 2014).

- Las administraciones públicas muestran disparidad en su postura hacia el sector, incluso si no se producen cambios en los equipos de gobierno. A ello hay que añadir que Ibiza se divide en cinco municipios con normativas muy distintas: restrictiva en Santa Eulària y Sant Joan; bastante control en Ibiza capital, y poco restrictivo en Sant Antoni y Sant Josep. Esta disparidad normativa molesta a empresarios como Ricardo Urgell, ya que los establecimientos de Pachá están en Ibiza capital (Pachá Ibiza, El Hotel y Cabaret Lío) y Santa Eulària (Destino Ibiza Pacha Resort):

"El gran problema que tiene lbiza es que en los 572 kilómetros cuadrados que tiene hay cinco municipios y en cada municipio se guisa el cordero diferente, cada uno hace lo que le da la gana, no hay orden ni concierto y tenemos competencias ilegales y desleales permitidas por los ayuntamientos.... La permisividad en Sant Antoni y Sant Josep ha sido total, ahí se ha hecho siempre lo que ha dado la gana. Si tu negocio está en un municipio no tan permisivo como lbiza ciudad o Santa Eulària, resulta que tienes una competencia desleal evidente" (Diario de Ibiza, 18 de noviembre de 2014).

Las discotecas, salas de fiestas y cafés concierto de lbiza facturan más de 400 millones de euros al año (el $50 \%$ del sector en Baleares) y dan trabajo a cerca de 8.000 personas (Diario de Ibiza, 13 de septiembre de 2014). Pero la mayor relevancia del sector se encuentra en su capacidad de atracción de turistas. El turismo de discotecas es el principal complemento del turismo de sol y playa. Juntos representan la mayor parte del negocio turístico de la isla. Por eso, el actual modelo turístico depende del turismo de discotecas.

El gran éxito mundial de lbiza limita la extensión de la temporada de las grandes discotecas y, por tanto, de la temporada turística. Las grandes fiestas y dj's del REDMARKA UIMA-Universidad de A Coruña - CIECID

Año VIII, Número 15, (2015), v I pp. 101-139

http://www.redmarka.net/ ISSN 1852-2300 
verano ibicenco se trasladan en invierno a las grandes discotecas del resto del mundo. Es una migración anual paralela a los turistas que genera un ciclo estacional en los establecimientos que es casi imposible de romper sin causar efectos mundiales en el sector.

Las líneas de futuro son muy diversas ya que este estudio es un primer acercamiento y porque los campos del management y el turismo tienen casi totalmente abandonado el sector de las discotecas. Faltan estudios históricos del fenómeno clubber y de las discotecas, son casi inexistentes los estudios descriptivos de la oferta, los trabajos de servicescape y de gestión de los negocios, etc.

\section{BIBLIOGRAFÍA}

Aguirre, B. E., Torres, M. R., Gill, K. B., \& Lawrence Hotchkiss, H. (2011). Normative collective behavior in the station building fire. Social Science Quarterly, 92(1), 100-118.

Allemand, R. (2010). De la mystification des pratiques à la négation du réel? Ethnographie de discothèques montpelliéraines. Deviance et Societe, 34(1), 2948.

Anderson, T. L., Daly, K., \& Rapp, L. (2009). Clubbing masculinities and crime: A qualitative study of Philadelphia nightclub scenes. Feminist Criminology, 4(4), 302-332.

Andersson, J. (2011). Vauxhall's post-industrial pleasure gardens: 'Death wish' and hedonism in 21st-century London. Urban Studies, 48(1), 85-100.

Archer, J.R.H. et al. (2014). Taking the Pissoir - A novel and reliable way of knowing what drugs are being used in nightclubs. Journal of Substance Use, 19(1-2), 103-107.

REDMARKA UIMA-Universidad de A Coruña - CIECID

Año VIII, Número 15, (2015), v I pp. 101-139

http://www.redmarka.net/ ISSN 1852-2300 
Austin, B. T. (1994). The construction and transformation of the American disc jockey occupation, 1950-1993. Ph.D., The University of Texas at Austin.

Bader, I., \& Scharenberg, A. (2010). The Sound of Berlin: Subculture and the global music industry. International Journal of Urban and Regional Research, 34(1), 76-91.

Bancroft, A. (2012). Drinking with and without fun: Female students' accounts of pre-drinking and club-drinking. Sociological Research Online, 17(4), 12-18.

Bar-Sela, S. M., \& Moisseiev, J. (2007). Valsalva retinopathy associated with vigorous dancing in a discotheque Ophthalmic Surgery Lasers \& Imaging, 38(1), 69-71.

Bellis, M. A., \& Hughes, K. (2004). Sexual behaviour of young people in international tourist resorts. Sexually Transmitted Infections, 80(1), 43-47.

Bellis, M. A., Hughes, K., Bennett, A., \& Thomson, R. (2003). The role of an international nightlife resort in the proliferation of recreational drugs. Addiction, 98(12), 1713-1721.

Bellis, M. A. et al. (2009). Relative contributions of holiday location and nationality to changes in recreational drug taking behaviour: A natural experiment in the Balearic Islands. European Addiction Research, 15(2), 78-86.

Berkley, B. J. (1996). Designing services with function analysis. Journal of Hospitality and Tourism Research, 20(1), 73-100.

Boyd, J. (2010). Producing vancouver's (hetero)normative nightscape. Gender, Place and Culture, 17(2), 169-189.

Burke, M., \& Schmidt, A. (2013). How should we plan and regulate live music in Australian cities? Learnings from Brisbane. Australian Planner, 50(1), 68-78.

Campo, D., \& Ryan, B. D. (2008). The entertainment zone: Unplanned nightlife and the revitalization of the American downtown. Journal of Urban Design, 13(3), 291-315.

REDMARKA UIMA-Universidad de A Coruña - CIECID

Año VIII, Número 15, (2015), v I pp. 101-139

http://www.redmarka.net/ ISSN 1852-2300 
Davis, A. M. (2008). Dragging identity: A critical ethnography of nightclub space(s). Ph.D., Bowling Green State University.

Demant, J. (2013). Affected in the nightclub. A case study of regular clubbers' conflictual practices in nightclubs. International Journal of Drug Policy, 24(3), 196-202.

Downing, J. et al. (2011). Factors associated with risky sexual behaviour: A comparison of British, Spanish and German holidaymakers to the Balearics. European Journal of Public Health, 21(3), 275-281.

Elliott, L. et al. (1998). Alcohol, drug use and sexual behaviour of young adults on a mediterranean dance holiday. Addiction Research and Theory, 6(4), 319340.

Fallin, A., Neilands, T. B., Jordan, J. W., \& Ling, P. M. (2014). Secondhand smoke exposure among young adult sexual minority bar and nightclub patrons. American Journal of Public Health, 104(2), 148-153.

Forsyth, A. J. M. (2009). 'Gritos de cerveza, cerveza': El rol de la música y de los DJs en el control del desorden en los clubes nocturnos. Adicciones, 21(4), 327345.

Forsyth, A. J. M., \& Lennox, J. C. (2010). Gender differences in the choreography of alcohol-related violence: An observational study of aggression within licensed premises. Journal of Substance Use, 15(2), 75-88.

García, C. M. (2005). Global salsa: The politics of Latinidad in Los Angeles nightclubs. Ph.D., University of California, Los Angeles.

Goulding, C., Shankar, A., Elliott, R., \& Canniford, R. (2009). The Marketplace Management of Illicit Pleasure. Journal of Consumer Research, 35(5), 759-771.

Hendrie, C. A., Mannion, H. D., \& Godfrey, G. K. (2009). Evidence to suggest that nightclubs function as human sexual display grounds. Behaviour, 146(10), 1331-1348.

REDMARKA UIMA-Universidad de A Coruña - CIECID

Año VIII, Número 15, (2015), v I pp. 101-139

http://www.redmarka.net/ ISSN 1852-2300 
Homan, S. (2010). Dancing without music: Copyright and Australian nightclubs. Popular Music and Society, 33(3), 377-393.

Hong, L. K., \& Duff, R. W. (1997). The center and the peripheral - Functions and locations of dance clubs in Los Angeles. Journal of Contemporary Ethnography, 26(2), 182-201.

Huang, J. (2011). Night on the town. Taiwan Review, 61(6), 18-21.

Hughes, K., \& Bellis, M. A. (2006). Sexual behaviour among casual workers in an international nightlife resort: a case control study. BMC Public Health, 6, art. กํㅜ 39.

Hughes, K., et al. (2008). Predictors of violence in young tourists: a comparative study of British, German and Spanish holidaymakers. European Journal of Public Health, 18(6), 569-574.

Hughes, K., et al. (2009). Alcohol, drugs, sex and violence: health risks and consequences in young British holidaymakers to the Balearics. Adicciones, 21(4), 265-277.

Jones, M. R., et al. (2013). Secondhand tobacco smoke: An occupational hazard for smoking and non-smoking bar and nightclub employees. Tobacco Control, 22(5), 308-314.

Kramer, S. et al. (2006). Efficacy of the antioxidant N-acetylcysteine (NAC) in protecting ears exposed to loud music. Journal of the American Academy of Audiology, 17(4), 265-278.

Krasnow, C. H. (1999). The development of aesthetic ideology in popular music: Rock and disco in the nineteen seventies. Ph.D., University of Minnesota.

Kubacki, K., Skinner, H., Parfitt, S., \& Moss, G. (2007). Comparing nightclub customers' preferences in existing and emerging markets. International Journal of Hospitality Management, 26(4), 957-973.

REDMARKA UIMA-Universidad de A Coruña - CIECID

Año VIII, Número 15, (2015), v I pp. 101-139

http://www.redmarka.net/ ISSN 1852-2300 
Lea, T., Reynolds, R., \& De Wit, J. (2013). Alcohol and club drug use among same-sex attracted young people: Associations with frequenting the lesbian and gay scene and other bars and nightclubs. Substance Use and Misuse, 48(1-2), 129-136.

Mahoney, E. J. et al. (2005). Lessons learned from a nightclub fire: Institutional disaster preparedness. Journal of Trauma - Injury, Infection and Critical Care, 58(3), 487-491.

McVeigh, M. (2004). Nightclub design: The significance of performance in 21st century culture. M.I.D., University of Manitoba (Canada).

Norrgård, E. et al. (2014). Environmental and capacity requirements are critical for implementing and sustaining a drug prevention program: As multiple case study of "Clubs against drugs". Substance Abuse: Treatment, Prevention, and Policy, 9(1), art. ㄲo. 6.

Oak, S., \& Schmidgall, R. S. (2009). Have Budgetary controls in the US club industry changed from the mid-1980s to the twenty-first century? International Journal of Contemporary Hospitality Management, 21(4), 411-421.

Planells, M. (1986). Ibiza, la senda de los elefantes, volumen II. Barcelona: Ediciones Obelisco S. A.

Planells, M. (2002). El nacimiento de Babel -Ibiza años 60-. Eivissa: José Ferrer y Vicent Guillamó.

Ramón, E. (2001). Historia del turismo en Ibiza y Formentera. 1900-2000. Eivissa: Genial Ediciones Culturals.

Ramón, J. \& Serra, A. (2013). Tolerancia y desarrollo turístico: Sant Antoni en los años cincuenta. CULTUR-Revista de Cultura e Turismo, 7(2), 132-156.

Réau, B. (2006). Enchantements nocturnes: ethnographie de deux discothèques parisiennes. Ethnologie Francaise, 36(2), 333-339.

REDMARKA UIMA-Universidad de A Coruña - CIECID

Año VIII, Número 15, (2015), v I pp. 101-139

http://www.redmarka.net/ ISSN 1852-2300 
Roberts, M., \& Gornostaeva, G. (2007). The night-time economy and sustainable town centres: Dilemmas for local government. International Journal of Sustainable Development and Planning, 2(2), 134-152.

Romain-Glassey, N., et al. (2012). When nightclub security agents assault clients. Journal of Forensic and Legal Medicine, 19(6), 341-344.

Rose, J. H. (1994). Playing out: A multiple case study of coordination and presentation in nightclub bands. Ph.D., University of Minnesota.

Skinner, H., Kubacki, K., Parfitt, S., \& Moss, G. (2008). Polish nightclubs and bars: Management insights into what customers really want. Journal for East European Management Studies, 13(2), 154-169.

Skinner, H., Moss, G., \& Parfitt, S. (2005). Nightclubs and bars: What do customers really want? International Journal of Contemporary Hospitality Management, 17(2), 114-124.

Sönmez, S., Apostolopoulos, Y., Theocharous, A., \& Massengale, K. (2013). Bar crawls, foam parties, and clubbing networks: Mapping the risk environment of a Mediterranean nightlife resort. Tourism Management Perspectives, 8, 49-59.

Sosteric, M. (1996). Subjectivity and the labour process: A case study in the restaurant industry. Work, Employment and Society, 10(2), 297-318.

Todorovic, M., \& Bakir, A. (2005). Inaudible noise: Belgrade's Academy Club: Legacy, old locals and new spaces. Leisure Studies, 24(4), 415-434.

Tuck, S. (2008). Introduction: Reconsidering the 1970s-The 1960s to a Disco Beat? Journal of Contemporary History, 43(4), 617-620.

Tutenges, S. (2009). Safety problems among heavy-drinking youth at a Bulgarian nightlife resort. International Journal of Drug Policy, 20(5), 444-446.

Tutenges, S. (2012). Nightlife tourism: A mixed methods study of young tourists at an international nightlife resort. Tourist Studies, 12(2), 132-150.

REDMARKA UIMA-Universidad de A Coruña - CIECID

Año VIII, Número 15, (2015), v I pp. 101-139

http://www.redmarka.net/ ISSN 1852-2300 
Weichbold, B., \& Zorowka, P. (2005). Führt eine schallpegelabsenkung in diskotheken zu einem rückgang der besucher? HNO, 53(10), 845-851.

Wells, B. E. et al. (2010). Patterns of alcohol consumption and sexual behavior among young adults in nightclubs. American Journal of Drug and Alcohol Abuse, 36(1), 39-45.

Wood, D. M., Hunter, L., Measham, F., \& Dargan, P. I. (2012). Limited use of novel psychoactive substances in South London nightclubs. QJM, 105(10), 959964.

\section{Paginas Web:}

http://elpais.com/elpais/eps.html

http://ibestat.caib.es/

http://ibiza-style.com

http://www.diariodeibiza.es/

http://www.elmundo.es/

http://www.top100clubs.com/

http://www.wintermusicconference.com/

https://sabi.bvdinfo.com

REDMARKA UIMA-Universidad de A Coruña - CIECID

Año VIII, Número 15, (2015), v I pp. 101-139

http://www.redmarka.net/ ISSN 1852-2300 